\title{
An Update on a Etiopathogenesis and Management of Obesity
}

\author{
Kulvinder Kochar Kaur ${ }^{1 *}$, Gautam Allahbadia ${ }^{2}$ and Mandeep Singh ${ }^{3}$ \\ ${ }^{1}$ Scientific Director, DR Kulvinder Kaur Centre for Human Reproduction, 721, G.T.B.Nagar, Jalandhar-144001, \\ Punjab, India \\ ${ }^{2}$ Scientific Director, Rotunda-A Centre for Human reproduction,672, KalpakGarden, Perry Cross Road, Near Otter's \\ Club, Bandra (W)-400040, Mumbai, India \\ ${ }^{3}$ Consultant Neurologist, Swami Satyanand Hospital, Near NawiKachehri, Baradri, Ladowaliroad, Jalandhar, Punjab
}

Received: : March 07, 2015; Accepted: November 14, 2016; Published: November 21, 2016

*Corresponding author: Kulvinder Kochar Kaur, Scientific Director, DR Kulvinder Kaur Centre for Human Reproduction, 721, G.T.B. Nagar, Jalandhar-144001, Punjab, India, Tel: 91-181-9872043422, 91-181-4613422; Fax-91-181-4613422; E-mail: kulvinder.dr@gmail.com

\begin{abstract}
Obesity constitutes a critical risk factor for the development insulin resistance and many life threatening diseases like insulin resistance and type 2 diabetes. Adipose tissue plays an important role in regulating whole body energy homeostasis and obesity related Insulin Resistance (IR). Inflammation has been linked to IR. AT has been demonstrated to be an important source for producing inflammatory molecules in obese state, primarily due to accumulation of macrophages, but recently monocytes and other classes of T cells like iNKT, Th17/21, Treg have also been implicated besides mast cells. Further a role of renin angiotensin system and angiotensin II receptor 1 in modulating leptins effects on increased energy expenditure is discussed. Roles of fibroblast growth factors, including that of FGFR1c is discussed in how they are helpful in achieving weight loss through bariatric surgery and effects of bile acid-FGF interactions. Since currently not many other medical options are available need of the hour is to develop newer pharmacotherapies which can replace bariatric surgery; the only definitive successful model available and get some permanent knifeless options as that is only for a limited number of patients. Developing newer pharmacotherapies utilizing the knowledge of increasing energy expenditure via nonshivering thermogenesis by the conversion of WAT to BAT by utilizing miRNA/siRNA strategies is required to develop novel therapies free of cardiovascular side effects which limit use of current agents like Qsymia or was responsible for sibutramine withdrawal to fight the current global obesity epidemic.
\end{abstract}

Methods: For this review we included data and relevant information obtained through a PUBMED database search for articles published in English from 1950 to 2015 which included the terms 'obesity", 'childhood obesity', a Etiopathogenesis and 'adipose tissue inflammation', 'brown adipose tissue', 'medical treatment', 'bariatric surgery' to update our information regarding a Etiopathogenesis and treatment of obesity.

Results: The electronic search yielded a total of 11,150 articles, of which 1262 were relevant to childhood obesity, 616 to medical treatment, 1100 to brown adipose tissue and 335 to adipose tissue inflammation. After ruling out duplicate studies and studies which we had already covered in our previous reviews pertaining to obesity regarding micro RNA's, Brown adipose tissue, Medical treatment we selected 170 studies to update our knowledge regarding etiopathogenesis of both childhood and adult obesity to be able to plan future newer strategies .No meta-analysis was conducted.

Keywords:White adipose tissue; Brown adipose tissue; Fibroblast growth factor receptor1; Bariatric surgery; Bile acids; Renin-angiotensin system; Angiotensin II receptor 1c in leptins action; Qsymia; Liraglutide

\section{Introduction}

According to the world health organization more than 1 billion adults are overweight and of these, at least 200 million men and 300 million women are clinically obese [1]. In a prospective study where over 9 million people were evaluated worldwide in the last three decades, it was found that average body mass index increased by $0.4-0.5 \mathrm{~kg} / \mathrm{m}^{2}$ per decade ,and subregion trends showed that the average Body Mass Index (BMI) increased by 1.4 $\mathrm{kg} / \mathrm{m}^{2}$ in men and $1.9 \mathrm{~kg} / \mathrm{m}^{2}$ in women per decade [2].

The World Health Organization (WHO) has compared this marked change in body composition to a 'Globally epidemic disease' [3]. In addition at least 155 million children worldwide are overweight or obese, according to the international obesity task force. According to WHO at least $50 \%$ of adults and $20 \%$ of children in UK and USA are currently overweight. Prevalence of overweight amongst Australian children has increased from 11\% in 1985 to $20 \%$ in 1995.Childhood obesity has tripled in Canadian last 20 years. In a recent study even in India more than $20-28 \%$ of adult males and $40-45 \%$ of adult females in urban Delhi were overweight and about $15-30 \%$ of children in urban areas were overweight by WHO standards [4].

The aim of this study was to provide an update on a Etiopathogenesis on both childhood obesity as well as adult obesity, with the idea of planning newer strategies for obesity as gradually one by one the older medical drugs are leaving the market e.g. sibutramine in view of cardiovascular side effects, and newer drugs which showed a great promise in terms of efficacy like rimonabant had to be withdrawn from the armentamarium in view of side effects like suicidal ideations. Bariatric surgery, though very effective, has its limitations. i) It can't be used for all patients of obesity with the rate at which obesity is increasing globally in an epidemic proportion. ii) The side effects of surgery in such a morbidly obese person with metabolic syndrome with associated morbidity and risk of mortality is not worth the 
risk. iii) The cost factor involved with bariatric surgery rules it out for every obese patient. Hence we try to make use of the understanding we have gathered from our experience of so many years, using bariatric surgery, besides utilizing the normal physiological means and explosion of research that has come in the field of Brown Adipocyte Tissue (BAT) and development of BAT within white Adipose Tissue (AT), namely 'brite' adipocytes in an attempt to reach some conclusion in solving an apparently impossible challenge.

\section{Obesity In Infancy and Early Childhood}

In a review comparing why breast feeding is superior to infant formula feeding [5] tried to explain how the development of both obesity as well as allergy could be tracked down to increased growth early in life. The nutrient sensitive kinas mechanistic target of rapamycin 1 (mTORC 1), is considered the master regulator of cell growth is activated mainly by amino acids. In contrast to breastfeeding, which has normal influence on milk proteins which release leucine and glutamine into the circulation, whey derived leucine stimulates insulin secretion; whereas casein derived amino acids stimulate hepatic IGF1 synthesis. Insulin and IGF1 via PI3K activate Akt that attenuates the inhibitory activity of the tuberous complex (TSC1-TSC2) towards RHEB, the GTPAse then finally activatesmTORC1.Glutamine enhances cellular leucine uptake that activates the RAG GTPAse; the essential step for Mtorc1activation in the lysosomal surface. Physiological Mtorc1 activation recruits normal activation of the kinase S-6-K1 that controls adipocyte differentiation and adequate expression of FoxP3 treg cells. Excessive protein uptake by artificial infant formula feeding enhances plasma levels of leucine, insulin and IGF1, overactivating Mtorc1. Overstuimulated S-6-K1 stimulates adipocyte differentiation and inhibits FoxP3+expression, thus promote in growth, adiposity and allergy development. tended to cause an excessive protein intake which possibly activates excessively the infant's mTORC 1 signaling pathways, which enhances S-6-K-1 mediated adipocyte differentiation while inhibiting growth as well as differentiation of Fox P3 regulatory T cells $\{$ Treg $\}$ which are found to be deficient in atopic individuals. Thus the 'early protein hypothesis' not only explains the development of diseases driven by the development of mTORC1 initiated increase in infant growth ,but also the development of mTORC1 driven diseases such as obesity and allergy due to an abnormal programming of metabolic and immunologic pathways postnatally which are mTORC1 axis driven Although growth and differentiation are inhibited, the adipocyte growth is enhanced by S-6-K1, which leads to obesity .In farm children similarly the intake of fresh unpasteurized cow's milk exhibit an allergy preventive effect associated with increased Fox3+Treg cell numbers. Bovine and human milk contain a large amount of exosomal miRNA's (miR's) which have been hypothesized to be involved in immune regulation postnatally [6-10]. miRNA's in milk are transported by membranous vesicles called exosomal which play a pivotal role for horizontal miRNA transfer [10] Unidirectional transfer of miRNA loaded exosomal from Tcell to Antigen Presenting Cells(APC) has recently been confirmed. Both Human and bovine milk have high content of exosomal
miRNA155 [7,8,11,12]. Admyra, et al. [9] demonstrated that incubation of human milk exosomal which had been isolated with human peripheral mononuclear cells increased the number of CD4+CD25+FoxP3+Treg cells in a dose dependent fashion. It has been shown that the ancient immune regulatory miRNA155 is required for the development of Treg cells.miRNA155 deficient mice have a reduced number of Treg cells both in thymus and in the periphery [13], FoxP3 binding to the promoter of , the gene which encodes miRNA155 [14-16]. Reviewed in [5] Concluding remarks-Uncontrolled excess protein supply in formula feeding is associated with absence of bioactive MRNA, which along with insufficient bifidobacteria act in a synergistic way to cause insufficient Treg maturation .Formula induced mTORC1overactivation is thus critical mechanism to explain accelerated postnatal growth, allergy and obesity development on an aberrant pathway.

\section{Obesity in childhood}

Lundgraf, et al. [17] demonstrated an increase in adipocyte size and number in early childhood obese vs lean children. This was accompanied by decrease in basal lipolytic activity which significantly enhanced Stromal vascular cell proliferation in vitro which explained the AT cell hypertrophy and hyperplasia. Macrophage infiltration underlying the formation of Crown Like Structures $\{$ CLS $\}$ was increased in AT of obese children from 6yrs.This was associated with higher High sensitivity C Reactive Protein( hsCRP) serum levels along with Insulin Resistance (IR).

\section{Oral hygiene and childhood obesity}

Association of Dental Caries and Obesity: Costasuna, et al. [18] studying the impact of relation of dental caries, food intake, oral hygiene and life style on obesity studied 96 healthy children between 6-11 years and found a direct association between dental caries and obesity as evident from a correlation between prevalence of dental caries in obese children.The analysis of food intake and deciduous teeth/permanent teeth, measured by Dual Xray Absorptiometry(DXA),demonstrated that specific dietary habits(intake of sugar-sweetened drinks, frequency of sugar intake limited to main meals, frequency of food intake between meals)may be considered risk factors , that are common to both dental caries and childhood obesity.

Role of Salivary secretions: Further various neuropeptides such as des acyl ghrelin, leptin also affect salivary secretion. Saliva gets secreted not only from parotid, submandibular and sublingual paired major glands but also several hundred minor glands spread over oral mucosa. Salivary secretion gets induced by salivary gland reflex on eating, is there on resting and even on sleeping and present during both biting and teeth grinding (bruxism) [19]. Besides components of saliva, like acyl ghrelin, des acyl ghrelin, other components observed along with histamine are IgA, epidermal and transforming growth factors and lysozymes. These have been shown to possess properties of growth and differentiation, besides that of wound healing [20]. Mostly secretion is controlled by Autonomic Nervous System (ANS), with parasympathetic nerves controlling the secretion of water and electrolytes while sympathetic nerve controlling 
protein secretion from acinar cells by exocytosis [21]. These secretions of saliva control innate immunity as well as defense at mucosal surface and both ghrelin as well as soluble IgA may play a regulatory role against inflammatory infections. These neuropeptides have been identified in saliva as well as their associated receptors being located in the salivary glands and in the nerve innervating the salivary glands Further salivary ghrelin levels in adolescents as well as children are known to correlate with Body Mass Index (BMI) [22]. The salivary secretion is stimulated through parasympathetic and sympathetic ganglion, parasympathetic ganglion receives its stimulus via Nucleus Tractus Solitarius (NTS) and sympathetic ganglion receives its input from the NTS via the spinal cord. Both ganglia regulate salivary secretion, parotid gland supplies ghrelin which circulates throughout body. Primary parasympathetic salivary centre send connections to Lateral Hypothalamus (LH), Para Ventricular Nucleus (PVN), Central nucleus of Amygdala (CeA) along with the PVN and Preoptic Area (POA) [23,24]. Obesity is associated with decreased salivation and thereby related to severe aspect of oral health such as caries and periodontitis. Hypo salivation is a severe morbidity that can lead to precipitous decline in oral hygiene which further leads to multifocal dental caries and periodontitis or even cardiac disorders [25].

Role of Salivary antioxidants: Recent studies have shown an association with dental caries and mild gingival inflammation with obese children [26]. Children who are overweight or obese have been shown to have accelerated dental development even after adjusting for age and gender [27]. Gunjalli, et al. conducted a study of 42 children (6-12 yrs, both sexes) from different schools in coastal Karnataka for total antioxidant capacity, oral hygiene index, and dentition status. They found that salivary total antioxidants were significantly high in overweight and obese children than their normal counterparts .Prevalence of dental caries was high in obese/overweight when compared to normal children. Normally oxidative stress and low grade silent inflammation, caused due to high levels of free radicals in the body as a result of the unavailability of antioxidants is the underlying cause of chronic diseases such as Diabetes Mellitus (DM), hypertension, heart diseases, premature ageing and even obesity [28], so it is paradoxical to find high content of salivary antioxidants in this study [29]. Conclusions-Thus both maintaining oral dental hygiene, including decreasing oral sweets intake and preservation of salivary secretions is important in preventing childhood obesity.

\section{White Adipocyte Differentiation}

The most important of this cascade of transcription factors controlling adipogenesis tightly is CCAAT/enhancer binding protein $\{\mathrm{C} / \mathrm{EBP}\}$ and Peroxisome Proliferator Activated Receptor $\gamma\{$ PPAR $\gamma$. Besides these several signaling molecules including wingless and INT 1 proteins $\{w n t\}$ and insulin modulate adipogenesis [30]. Further PPAR $\gamma$ has been shown to be the major driver of the accumulation of phenotype of AT T reg cell .This was in keeping with that PPAR $\gamma$ expression by Visceral Adipose Tissue (VAT) Treg cells was necessary for complex restoration of insulin sensitivity in obese mice by the thiazolidinedione drug pioglitazone [31].

\section{Brown Adipocyte differentiation}

The difference thermogenic adipocytes have from white adipocytes is that they have greater number of mitochondria which are rich in Uncoupling Protein 1(UCP1). UCP1 normally increase heat production by uncoupling substrate oxidation from ATP production [32]. Besides that recently it has been shown that UCP-1 expressing adipocytes can get recruited from white adipocytes themselves which are the so called brite/beige adipocytes on cold exposure, a process which has been termed 'White browning' [33-37].

Thermogenic adipocytes have a substantial impact on the energy balance, as UCP1 -promoted heat production nonshivering thermogenesis-is a highly energy dissipating process [38, 39]. Thus utilizing this action of generating thermogenic adipocytes by White Adipose Tissue (WAT) browning and promoting increasing combustion in the adipose organ by nonshivering thermogenesis might help in developing novel antiobesity strategies [40]. Karbeiner, et al. [41] explored the function of miRNAs in different adipose tissue depots, which could result in novel therapeutic approaches to treat obesity in humans but as most miR's in the context have been characterized solely in mice there is a great demand for human studies. Karbeiner, et al [41]. The increase in energy expenditure can be achieved either by physical activity, which helps in utilization of calories in the form of exercise, mainly in the muscle, or nonshivering thermogenesis in the AT [42], owing to the fact that active (i.e. Thermogenic) brown adipose tissue (BAT) has recently been rediscovered in adult humans [43-46]. Further the group of Spiegelman have emphasized on how the embryogenesis of white and brown adipocytes differs i) Engrailed 1 expression is seen in dermatomyoma which are precursors of dermis, skeletal muscle and brown adipocytes [47]. ii) Brown adipocytes express same microRNAs as muscle i.e. micromeres [48]. iii) Depletion of PRD1-BF1-RIZ1 homologous domain containing protein 16(PRDM16) from primary brown fat leads to skeletal muscle differentiation. iv) Both skeletal muscle and brown adipocytes are derived from cells previously activated by myogenic factor 5(Myf5). v)Bone morphogenetic protein2(BMP2) and BMP4 promote white adipocyte differentiation while BMP7 selectively stimulates brown adipocytes and also stimulates PRDM 16 and UCP 1 development which all show that white and brown adipocytes are from different lineage [49]. Subsequently Petrovic et al further highlighted a component of white adipocytes which were thermogenically competent and could produce UCP-1 under chronic Peroxisome Proliferator Activated Receptor $\gamma$ (PPAR $\gamma$ ) in epididymally white adipocytes which were molecularly different from classic brown adipocytes [35].

Hence based on these studies [34,35], these adipocytes were differentiated by molecular markers Lhx8 and Zic (zinc in cerebellum) for brown, Thx15 (T-box15) for brown and brite, Hoxc9 and Shox2. 2 for brite/beige, Hoxc8, Inhbb (inhibin b) and Dermantopontin (Dp) for brite/white and Transcription factor 21(Tcf21) for white adipocytes [34, 35] (figure 1) have been defined. Further surface markers like amino acid transporters ASC1, PAT2 and purinergic receptor P2RX5 for white, beige / 


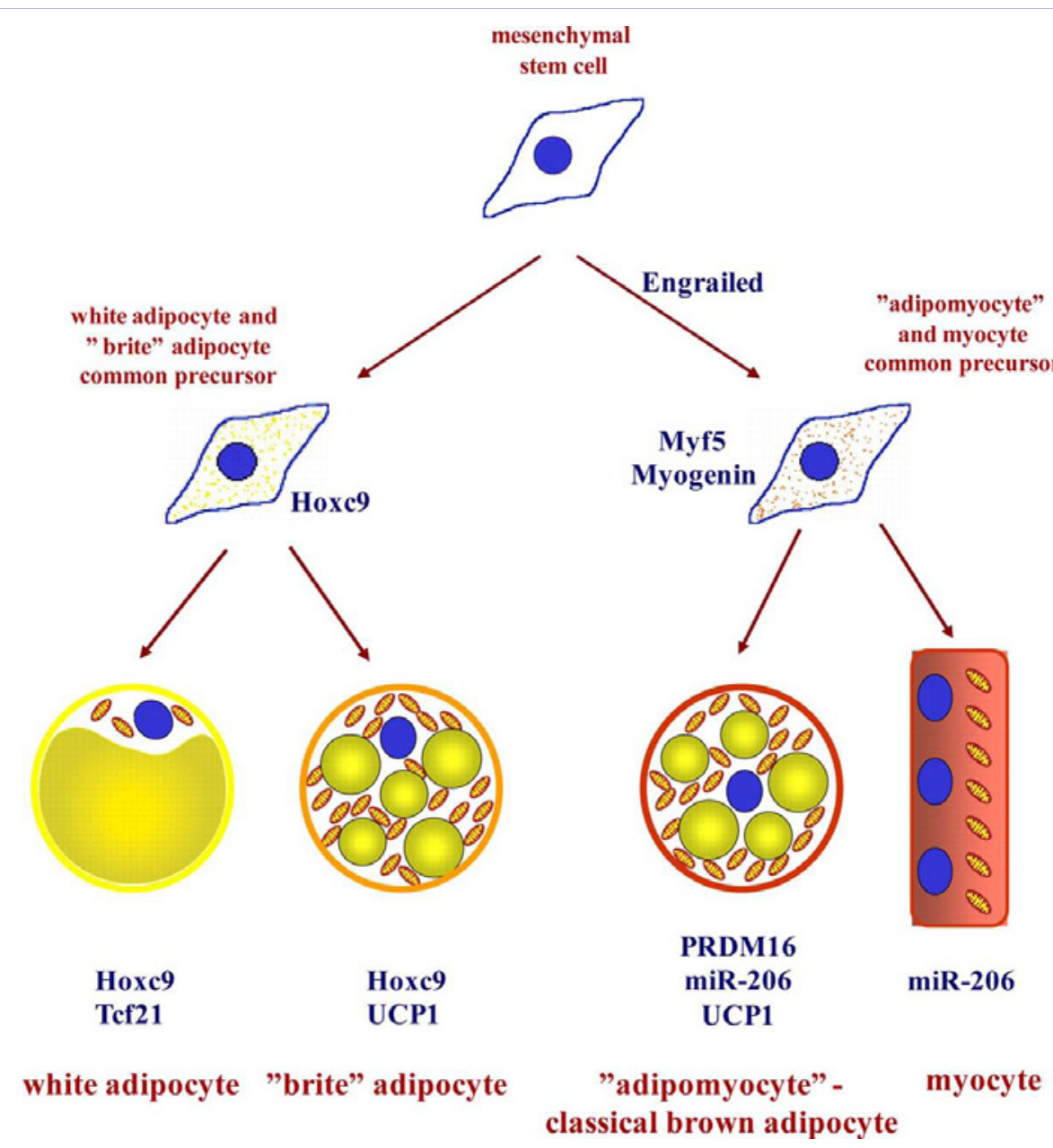

Figure 1: Courtesy ref 35----Subtypes of adipocytes and their origins This study along with study by Atit et al, Timmons et al and Seale et al (47,48and 49 respectively) implies that (atleast types of adipocytes should be distinguished; the classical brown adipocytes (the adipocytes), the brite adipocytes (i.e. the brown adipocyte -like adipocyte induced in the white adipocyte cultures), and the genuine whit adipocyte. The adipomyocytes share their origin with myocytes, whereas brite and white adipocytes have a different origin.

brite and brown adipocytes respectively have been defined [50]. The unique thermogenic capacity of BAT results from expression of uncoupling protein 1(UCP1) in the mitochondrial inner membrane. On recently finding that adult humans have functionally active BAT, it is now recognized that brown like adipocytes can be recruited in WAT upon environmental stimulation and pharmacological treatment related to this change is associated with increased energy expenditure, contributing to lean and healthy phenotype. Thus the promotion of brown like adipocytes development in WAT offers novel possibilities for the development of therapeutic strategies to combat obesity and related metabolic diseases. Cardiac Natriuretic Peptides (NP) and $\beta$ adrenergic receptor agonists are similarly potent at stimulating lipolysis in human adipocytes. Atrial Natriuretic Peptides (ANP) and ventricular BNP act by activating PPAR $\gamma$ co activator $1 \alpha$ (PGC1 $\alpha$ ) induced mitochondriogenesis and increase uncoupled and total respiration. At low concentration ANP and $\beta$-AR additively enhance expression of brown fat and mitochondrial markers in p38 MAPK-dependent manner. On exposure to cold temperature mice had increased level of circulating NP as well as higher expression of NP signaling receptor and lower level of the clearance receptor (Nprc) in BAT and WAT. NPRC+/-mice had markedly smaller BAT and WAT depots but higher thermogenic genes e.g. Ucp1.BNP infusion robustly increased Ucp1/Pgc1 $\alpha$ in WAT and BAT with corresponding elevation of respiration and energy expenditures. Thus Bodicherra et al showed that NP's promote browning of white adipocytes to increase energy expenditure, defining the heart as a central regulator of AT biology [51]. Thus growing attention is there in search for molecular pathways, pharmacological agents and endogenous signals that regulate the formation of thermogenic adipocytes [52-54]. Promising Targets have already been identified comprising endocrine and paracrine mediators e.g. fibroblast growth factor 21(FGF21) [55-57], NP’S [51,58,59], BMP7/8 [60,61], Orexin, et al. [62] as well as transcriptional regulators such as PPAR $\gamma 2, \mathrm{C} /$ EBP and PRDM16 [63]. 


\section{Role of Interferon regulatory factor 4(IRF4) in control of PGC1 $\alpha$ :}

Interferon Regulatory Factor 4 (IRF4) has been identified as a dominant transcriptional co activator along with PGC- $1 \alpha$. This gets induced by cAMP and cold in adipocytes associated with greater gene expression, cold tolerance and energy expenditure which is absent in IRF4 knockouts [64].

Further Ma X, et al. [65] differentiated white adipocytes into subcutaneous and visceral white AT based on their functional significance and emphasized how having some degree of subcutaneous fat is useful from point of view of adipokines they secrete e.g. leptin and adiponectin and in patients with lipodystrophies. For e.g. hepatic steatosis, dyslipidemia, IR are present in various congenital and acquired lipodystrophies, secondary to i)a diversion of lipid away from an inadequate AT reservoir to 'ectopic sites' e.g. liver and muscle. Secondly because of lack of secretion of the favourable adipokines like leptin and adiponectin due to lack of adequate AT. In this case, low leptin explains the increased appetite and inappropriately positive energy balance and decreased levels of both adipokines contribute to reduced activity of AMP activated protein kinase (AMPK) which promotes lipid oxidation. They clarified on how not having subcutaneous fat is harmful and emphasized on the significance of transcription factor islet 1 which has been recently highlighted in being important for development of cardiac, neuronal and pancreatic islet development and whose over expression causes down regulation of master transcriptional regulator PPAR $-\gamma$ by down regulation of bone morphogenetic protein 4(BMP4), although further work on these is needed. This was found specific to Visceral Adipose Tissue (VAT) and not found in Subcutaneous AT (SAT) [66]. Thus to summarize the basic control of differentiation is similar in BAT, but the differences include the effect of PGC-1 $\alpha$ on mitochondrial biosynthesis and up regulation of UCP1, with PRDM16 playing a pivotal role in expression of the BAT phenotype with IRF4 having a strong transcriptional influence on PGC-1- $\alpha$.Modulation of the capacity or function of these different AT depots, by altering adipocyte differentiation or other means ,holds promise for interventions that can be helpful in human disease associated with worldwide explosion of obesity or associated cardio metabolic disorders [65].

\section{Role of Breast Cancer 1( BrCA1):}

Although there is a decrease in lipogenic enzymes in obese and overweight subjects, simultaneously there is recruitment and proliferation of pre adipocytes [66]. No mechanism has been given to explain these paradoxical findings. Although in hepatocytes sterol regulatory element binding proteins 1c (SREBP 1c) is a well accepted transcription factor for the regulation of lipogenic enzymes, the mechanisms of lipogenic genes regulation in adipocytes remains unclear. Disruption of SREBP1c genetically did not cause changes in lipogenic gene expression in AT [67], and increases in SREBP 1c are not accompanied by transactivation of lipogenic genes in adipocytes, unlike the hepatocytes [68]. Hence Ortega, et al. evaluated $\mathrm{Br}$ Ca1 gene expression and protein levels in human AT, and both murine as well as human adipocytes. The principal findings were
- The increased expression of BrCa1 in both omental (OM) and subcutaneous (SC) fat depots by 1.36 fold and 1.49 fold

- Higher expression in SC as compared to $\mathrm{OM}$ fat respectively

- Simultaneously there was an increase in Phosphorylated Acetyl CoA Carboxylase (P-ACC) in SC and OM fat from obese subjects

- Both BrCa 1mRNA and protein increased by 3.5 fold and 1.2 fold respectively *the increase expression of BrCa1 mRNA in mature adipocytes when compared to Stromal Vascular Cells (SVC's) and the down regulation of BrCa 1 gene expression and protein during differentiation of both murine and human adipocytes, which can be restored by the macrophage LPS -conditioned medium which simulates inflammatory situation, whereas lipogenic enzymes significantly decreased.

- In parallel with increased BrCa1 mRNA P-ACC was also up regulated in $\mathrm{SC}$ as well as $\mathrm{OM}$ fat from obese subjects. PACC, decreased during differentiation of human adipocytes .Thus Ortega et al concluded that these special findings of BrCa1 and lipogenic enzymes in AT and adipocytes suggested that BrCa1 might help to control fatty acid biosynthesis in adipocytes and AT of obese subjects [69]. Further Deleted in Breast Cancer (DBC1) has been shown to play a functional role in adipocyte differentiation, although decreased in VAT and SAT of obese as compared to lean subjects, Dbc 1 knockdown with lentivirus led to enhanced adipocyte differentiation, increasing intracellular lipid accumulation and adipogenic gene expression which suggests DBC1 might promote VAT dysfunction [70].

\section{Etiopathogenesis of role of AT in Inflammation:}

Adipose Tissue $\{\mathrm{AT}\}$ is increasingly being recognized as a key regulator of whole body energy homeostasis and consequently as a prime therapeutic target for Metabolic Syndrome $\{\mathrm{MS}$. A substantial continuing growing body of evidence supports the concept that chronic low grade inflammation is a central characteristic of obesity contributing to development of Insulin Resistance $\{\mathrm{IR}\}$ in AT and other target organs including muscle, liver and the vasculature [71-73]. The field of immunometabolism has now expanded to include studies of the interactions of many types of immune cells with adipocytes [74,75]. Changes in gut microbiota like decreased Bacteroides and increased Firmicutes in obesity have been associated with greater metabolic Endotoxemia , inflammation with greater number of F4/80 positive macrophage infiltration affecting whole body metabolism along with energy homeostasis but this seems to have multiple levels of origin which is not clear [76-78].

These, gut microbiota not only modify local but systemic inflammatory reactions as well which influence, distant tissues, especially peripheral blood and AT, mainly its visceral compartment where ,via the portal vein ,intestinal microbial 
products are being directly drained into [76,79]. Both obesity and T2DM were found to be associated with changes in the amount and composition of gut microbes in experimental animals as well as humans as shown by Cani, et al. [76-80]. Various products that get derived from these, different types of commensal gut microbiota, exert both pro inflammatory as well as anti-inflammatory effects, as shown by Cani, et al. Lipopolysaccharide get translocated into systemic circulation which has been associated with metabolic Endotoxemia, and has been suggested as one of the main triggers of AT and systemic low grade inflammation [76,77]. In contrast the products of gut bacterial fermentation of ingested dietary fiber, especially Short Chain Fatty Acids (SCFA)-mainly butyrate, propionate and acetate which constitute 90\%of SCFA's were shown to have anti inflammatory effects and influence energy homeostasis [81]. They act through the Gprotein coupled receptors 41(GPCR41)/FFAR3 and 43(GPCR43)/FFAR2that are abundantly found in AT, as well as on immune cells, including peripheral blood mononuclear cells, eosinophils, and neutrophils. SCFA's (especially butyrate were able to reduce cell adhesion and chemo taxis , as reviewed by Meijer et al and thus at least partially prevent infiltration of immune cells into AT $[81,82]$. Treatment with propionate down regulated pro inflammatory cytokines/ chemokines like tumor necrosis factor- $\alpha(\mathrm{TNF}-\alpha)$ and CCL- 5 from AT explants along with macrophages while increasing protein lipases and GLUT4 associated with lipogenesis and increased glucose uptake. Thus AL-Lahlan concluded that propionic acid produced by colon may have a direct beneficial effect in reducing inflammation [83].

SCFA's were further able to inhibit the activation and proliferation of T cells and adhesion of Antigen Processing Cells (APC s) contributing to their inflammation reducing properties [83]. The epithelium of the intestine is the first organ to come in contact with the digested food and nutrients. Hence it also becomes the biggest surface for crosstalk with the outer part of the body, including that with the gut microbes. The intestinal innate immune system along with intestinal innate immune receptors like NOD2 /Inflammasome component NOD like receptor and other receptors play an important role under normal physiological conditions in maintaining the interactions between gut microbiota and the host. This symbiosis may occur through a fine tuned mechanism leading to pathogen destruction and conversely, to the tolerance of commensal by selecting strategies to create ecological niches for beneficial and stably associated microbiota $[84,85]$. Recognition of pathogen associated molecular patterns by epithelial cells through several effector systems (that is Pathogen Recognition Receptors (PRR)) is important for this balance. MyD88 (myeloid differentiation primary response gene 88)is a central adaptor molecule for the major Toll Like Receptors(TLR's)which are the most studied PRR.MyD88 is a protein that is at the interface of the interaction between microorganisms and the host. In view of conflicting reports regarding protection against diet induced obesity (DIO) in whole body deletion of TLR/MyD88, Everard, et al. reported that specifically deleting epithelial MyD88 could afford partial protection against disease like diabetes, DIO, and inflammation. This is associated with increased energy expenditure, improved glucose homeostasis, reduced hepatic steatosis, fat mass and inflammation. Protection is transferred following gut microbiota transplantation to germ free recipients. They also demonstrated that intestinal epithelial My D88 deletion increases antiinflammatory endocannabinoid, restores antimicrobial peptides production and increases intestinal regulatory Tcells during DIO. Targeting MyD88 after the onset of obesity reduces fat mass and inflammation. Thus they identified intestinal epithelia MyD88 to be able to sense the metabolism of host as per their nutritional status and could offer to be a putative therapeutic target for obesity and related disorders [86]. Krinninger, et al. addressed the issue of recruitment of inflammatory cells into AT. They examined monocytes (circulating precursors of macrophages) from obese/normal weight women to determine whether phenotypic differences existed that could promote accumulation of pro inflammatory macrophages in AT. They found that the total monocyte population in obese women contains a greater percentage of activated CD14+CD16+monocytes than in normal weight women. Monocytes from obese women also exhibited increased surface expression of chemokine receptors, CC motif Chemokine Ligand 2 receptor (CCR2), Chemokine Ligand 3 Receptor (CCR5).They also enhanced in vitro migratory response to the chemokines Monocyte Chemotactic protein 1(MCP1) and Regulated on activation normally on Tcells expressed and secreted (RANTES), the production of which is increased in AT of obese subjects [87]. The authors concluded that circulating monocytes in obese women are in an activated proinflammatory state and that they are primed to migrate into AT in response to enhanced Chemotactic signals from the tissues in obesity [88]. Human monocytes are phenotypically heterogeneous and in general are classified according to expression of surface markers CD14 and CD16 [73]. Classical CD14 +CD16 monocytes constitute approximately $80 \%$ of the circulating monocytes. Monocytes positive for CD16 expression (CD14+CD16+) occurs in inflammatory situations like sepsis, rheumatoid arthritis etc. These cells express a greater macrophage like phenotype, have greater binding affinity for endothelial cell and increase release of TNF $-\alpha$ and other proinflammatory cytokines, and have greater antigen binding capacity.CD16 monocytes can be phenotypically heterogeneous with CD14 expression varying from very low to high(a characteristic that was not studied by Krinninger et al). Krinninger et al not only found a greater percentage of circulating CD14+CD16+monocytes in obese women, as seen in a previous study by Poitou, et al. [89], but also found that CCR2and CCR5 expression and/or density of receptors is increased across the entire population of CD14+CD16 and CD14+CD16+ monocytes. The greater chemokine receptor expression and enhanced in vitro migratory capacity strongly suggests that increase in macrophages in AT of obese humans results, atleast in part, from recruitment of new cells into the tissue [87].

\section{Role of Renin -Angiotensin System}

The renin-angiotensin system (RAS), long known for its role in BP and fluid balance, is now emerging as a key regulator of metabolic control. While activation of the systemic RAS results in adipogenesis and weight gain [90-92], recent evidence 
indicates that activation of the CNS RAS has the opposite effect and promotes a lean phenotype. Brain infusion of Angiotensin II (Ang II) in rats [93,94], or genetic over expression of the RAS components in the CNS of mice [95], both result in an increase in thermogenic energy expenditure.

Importantly the energy expenditure of brain RAS activation are similar to the actions of the adipocyte derived hormone leptin ,suggesting that the metabolic influence of brain Ang II maybe due ,in part to an interaction with central leptin signaling , Facilitatory leptin-RAS relationship has been demonstrated in the periphery in line with this $[96,97]$. Moreover leptin and AngII type1a receptors (AT1Ar) are co expressed in a number of forebrain $[98,99]$, hypothalamus $[100,101]$ and brain stem [102-104] regions that are implicated in metabolism and energy expenditure [105]. Using (AT1Ar) knockout mice, Hilzendeger, et al. [105] previously identified a brain interaction between leptin and RAS in the regulation of Sympathetic Nerve Activity (SNA) but the brain regions, or metabolic effects of this interaction remained unknown. Young et al testing the hypothesis that AT1Ar in the brain is involved in the metabolic actions of leptin showed.

Sub Fornical Organ (SFO), a tiny forebrain structure situated outside the Blood Brain Barrier (BBB), dense with AT1Ar and recently implicated as an integrative metabolic centre [106108], plays a previously unrecognized role in the control of body weight. Interaction between SFO-AT1Ar and CNS leptin in the regulation of BAT thermogenic metabolism and body when AT1Ar are selectively deleted from SFO, sympathetically mediated BAT thermogenesis and decrease in body weight in response to leptin are significantly blunted, independent of changes in locomotor activity and food intake [109].

\section{Role of angiotensin II receptor blockers (ARB) ON FABP4 (fatty acid binding protein 4)}

Increase in circulated fatty acid binding protein 4(FABP4) in the serum also known as Ap2 (FABP4/ A-FABP-Ap2), is usually found to be correlated with a hypertension, obesity, IR along with some cardiovascular event. To understand how circulating FABP4 is modified by pharmacological agents Funahashi et al studied the effects of various angiotensin II receptor blockers (ARB's) on serum Ap2 levels. First .essential hypertensive's were treated with ARB's: candesartan (8 mg/day, $\mathrm{n}=7$ ) for 2 weeks, olmesartan (20 mg/ day, $\mathrm{n}=9$ ) for 12 weeks, and valsartan ( $80 \mathrm{mg} /$ day, $\mathrm{n}=94$ ) or telmisartan $(40 \mathrm{mg} /$ day, $\mathrm{n}=91$ ) for 8 weeks added to amlodipine $5 \mathrm{mg} /$ day. Treatment with ARB's significantly decreased BP and serum FABP4concentrationsby 8-20\% which was not associated with any significant changes in other adiposity or lipid variables these were determined by hyperinsulinemic euglycemic glucose clamp which is considered, a sensitive index of insulin sensitivity, was significantly increased by candesartan. Next the changes in Ap2 secretion from 3 T3-L1 adipocytes were examined under several agents. Increasing Lipolysis by stimulating $\beta$-adrenoceptor in 3T3L1adipocytes by isoproterenol increased FABP4 secretion while on the opposite, insulin suppressed FABP4 secretion. No effect on gene expression/ secretion of Ap2 was found on treatment of 3T3-L1 adipocytes with angiotensin or ARB's irrespective of adrenoceptor stimulation. Hence they concluded that treatment with structurally different ARB's similarly decrease circulating FABP4 concentrations in hypertensive patients as a class effect of ARB's, which one could not attribute to angiotensin II receptor blockade in adipocytes. Reduction in FABP4 levels by ARB's might be involved in the suppression of cardiovascular events [110].

\section{Role Of CNS \\ Central FA Sensing}

Fatty acid sensing neurons in particular areas of hypothalamus sense the variations in plasma fatty acid (FA) concentrations detected by FA sensing neurons. LeFoll, et al. previously showed in vitro that at least $50 \%$ of the FA sensing neurons on Ventro Medial Hypothalamus (VMH) neurons are attributable to the interaction of long chain FA translocase/CD36 (CD36). Mouilli, et al. tried to assesses the in vivo effects of intrahypothalamic FA sensing is partly mediated by CD36 / intracellular events such as acyl CoA synthase/ or $\beta$ oxidation. For that they put in, a catheter within the carotid artery toward the brain in male wistar rats. Following one week of recovery animals were food deprived for $5 \mathrm{~h}$, then received $10 \mathrm{~min}$ infusions of triglyceride emulsion .Intra lipid +/-heparin (IL, ILH respectively)or Saline Heparin(SH) were carried out and food intake was assessed over the next 5h.Experimental groups included i)Rats previously injected in the VM nucleus with sh RNA against CD36 or scrambled RNAII) Etomoxir(CPT1 inhibitor) or saline infused with ILH/SH; and iii) Triacsin C(Acyl CoA synthase inhibitor) or saline infused with ILH/ SH. ILH significantly lowered food intake during refeeding , compared to $\mathrm{SH}(\mathrm{P}<0.001)$.Five hours after refeeding, Etomoxir did not affect this inhibitory effect of ILH on food intake while VMN CD36 depletion totally prevented it. Triacsin $\mathrm{C}$ also prevented ILH effects on food intake. Hence this made them conclude that the effect of FA to inhibit food intake is dependent on VMN CD36 and acyl CoA synthesis but without requiring FA oxidation [111].

\section{Role of Fibroblast growth factor receptor 1(FGFR1)}

There are 22 members in the mammalian Fibroblast Growth Factor (FGF) family along with 4 FGFRs which have been identified as existing in different splice variants with different Ligand binding specificities [112,113]. Itoh N, et al. [114] studying the SNP in 4 groups of obese patients identified FGFR 1 SNPrs7012413* $\mathrm{T}$ to be increased in adipose tissue but not skeletal muscle in obese cohorts. In addition, AT FGFR1 mRNA and protein levels were increased in the hypothalamus of DIO rats [114]. Hence they considered FGFR1 to be a novel human obesity candidate gene that may affect control of food intake and metabolism. Weight loss was caused by Reversible hypophagia, which was induced by antagonizing FGFR1c with the Monoclonal Antibody (mAb) IMC-A1 in animals [115]. Paradoxically, an FGFR1-activating mAb was also found to cause body weight loss in mice via a combination of both decreased food intake and increased energy expenditure [116]. Lelliott, et al. generated a monoclonal antibody which targeted human FGFR1c (R1cmAb) that caused profound body weight and body 
fat loss in diet induced obese mice due to decreased food intake (without affecting energy expenditure), in turn improving glucose control.R1 cmAb along with causing weight loss in leptin receptor mutant $\mathrm{db} / \mathrm{db}$ mice and leptin deficient ob/ob mice, and in mice lacking either the melanocortin 4 receptor or melanin concentrating hormone receptor1. In addition $\mathrm{R} 1 \mathrm{cmAb}$ did not change hypothalamic mRNA levels of known hypothalamic genes involved in food intake from arcuate like Agrp, Cart, Pomc, Npy or from lateral hypothalamus like, Mch or Orexin, or PVN like Crh suggesting that $\mathrm{R} 1 \mathrm{cmAb}$ could cause food inhibition and body weight loss via other mechanisms in the brain. On Peripheral administration R1cmAb got accumulated not only in the median eminence, but also adjacent arcuate nucleus along with the circum ventricular organs where it activated the early response gene c-fos expression. Hence it was proposed that possibly with inhibition of food intake $\mathrm{R} 1 \mathrm{cmAb}$ simultaneously deceased monocyte chemo attractant protein 1 and 3 along with ERK1/2 and p70 S6 kinase 1 activation [117].

\section{Role of new genes/pathways in CNS}

Locke, et al. conducted a genome-wide association study and Metabochip meta-analysis of BMI, a measure commonly used to define obesity and assess adiposity in over 3 lakh individuals. This analysis identified 97 BMI associated loci $(p<5 \times 10(-8))$, 56 of which are novel. Five loci demonstrate clear evidence of several independent association signals, and many loci have significant effects on other metabolic phenotypes. The 97 loci account for $2.7 \%$ of BMI variation. Central nervous system role is strongly supported by pathway analysis in obesity susceptibility which provides roles of new genes and pathways, especially with those related to synaptic function, glutamate signaling, insulin secretion along with, energy metabolism, lipid biology and adipogenesis, hence implicating involvement of CNS genes in obesity [118].

\section{Management Of Obesity}

Dietary therapy by itself is ineffective usually, whereas bariatric surgery, which is successful, is quite demanding and cannot be used in all cases of obesity besides that due to the risks of surgery, it gets used in a minimal number of patients. A lot of emphasis is being laid on increasing energy expenditure with the use of increased physical activity through some exercises which not only generate FNDC5 which is a natural precursor for irisin which increasing browning of white adipocytes into 'brite' besides the trials of recombinant irisin for the purpose..To obviate the negative effects of bariatric surgery, a lot of endoscopic surgeries have been developed as a link between the two.

\section{Role of Bariatric Surgery (BS)}

Shin and Berthoud HR, et al. has reviewed why BS has superior efficacy and how obesity surgery works and how exactly we can use it for developing newer medical therapies [119]. Changes in gut-brain signaling, hormones, bile acids and still other unidentified factors remain an important factor. Both Roux -en -Y gastric bypass surgery(RYGB) and sleeve gastrectomy result in increased levels of circulating bile acids
[120-123], which can signal through the membrane receptor TGR5 and nuclear receptor FXR to a number of organs [124-127]. The conjugated bile acid tauroursodeoxycholic acid (TUDCA) which decreases endoplasmic stress, is a potent leptin sensitizer in the hypothalamus of obese mice [128] and results in changes of body weight set point directly. Also the feedback control loop that regulates the total pool of bile acids also involves FXRmediated stimulation of FGF9 in humans and FGF15 in mice[124] and the levels of FGF21 as well asFGF19 are altered significantly following RYGB surgery[124] and further FGF21 is known to improve glucose and body weight homeostasis through multiple pathways $[111,129,130]$. Besides that the powerful body weight lowering effect of monoclonal antibodies to the FGF1c R that have partial agonistic activity [110], suggest the possibility that that the bile acid-FGF signaling pathway maybe crucial for the success of RYGB and sleeve gastrectomy. Further bile acid signaling through the membrane receptor TGR5 has been found to increase brown fat thermogenesis [131]and glucagon like peptide1 (GLP1) secretion [132]. By increasing brown fat thermogenesis it helps in increasing energy expenditure besides improvement in the glycemic profile which GLP1 achieves, both in terms of fat reduction as well as improved glucose homeostasis.

By resensitizing homeostatic regulating circuits in the hypothalamus and hedonic processing in the corticolimbic to internal signals bariatric surgery could lead to a state of being content with less [133,134](figure 2).

\section{Role of Endoscopic Therapy for weight loss: Gastroplasty, duodenal sleeves, intragastric balloons, aspiration}

In between medical treatment and BS Endoscopic surgery gives the following advantages, being potentially repeatable, they are less invasive with lower cost than medical /surgical alternatives. Restrictive, bypass, space occupying or aspiration therapy are some of the available endoscopic procedures for weight loss. Restrictive include the USGI primary obesity surgery endoluminal procedure (Incision less operating platform which can perform full thickness plication, endoscopic sleeve gastroplasty using Apollo Overstitch), Transoral gastroplasty, gastric volume reduction using the endobarrier duodenal jejunal by pass liner. Intragastric balloons, transpyloric shuttle and Sati sphere. The Aspire assist Aspiration system and endoscopic revision of gastric bypass to address weight gain has been studied using Apollo overstitch [130]. They concluded that endoscopic therapies for weight loss are potentially reversible, repeatable, less invasive and have lower cost, than various medical and surgical alternatives. With the variety of devices under development, in clinical trials and currently in use, patients will have multiple endoscopic options with greater efficacy than medical therapies and a lower invasiveness and greater accessibility than surgery.

\section{Role of Medical Therapy for weight loss}

In the past 20 years there have been a lot of hurdles because of marked side effects; however several new drugs for obesity therapy are not licensed in all parts of the world or have 


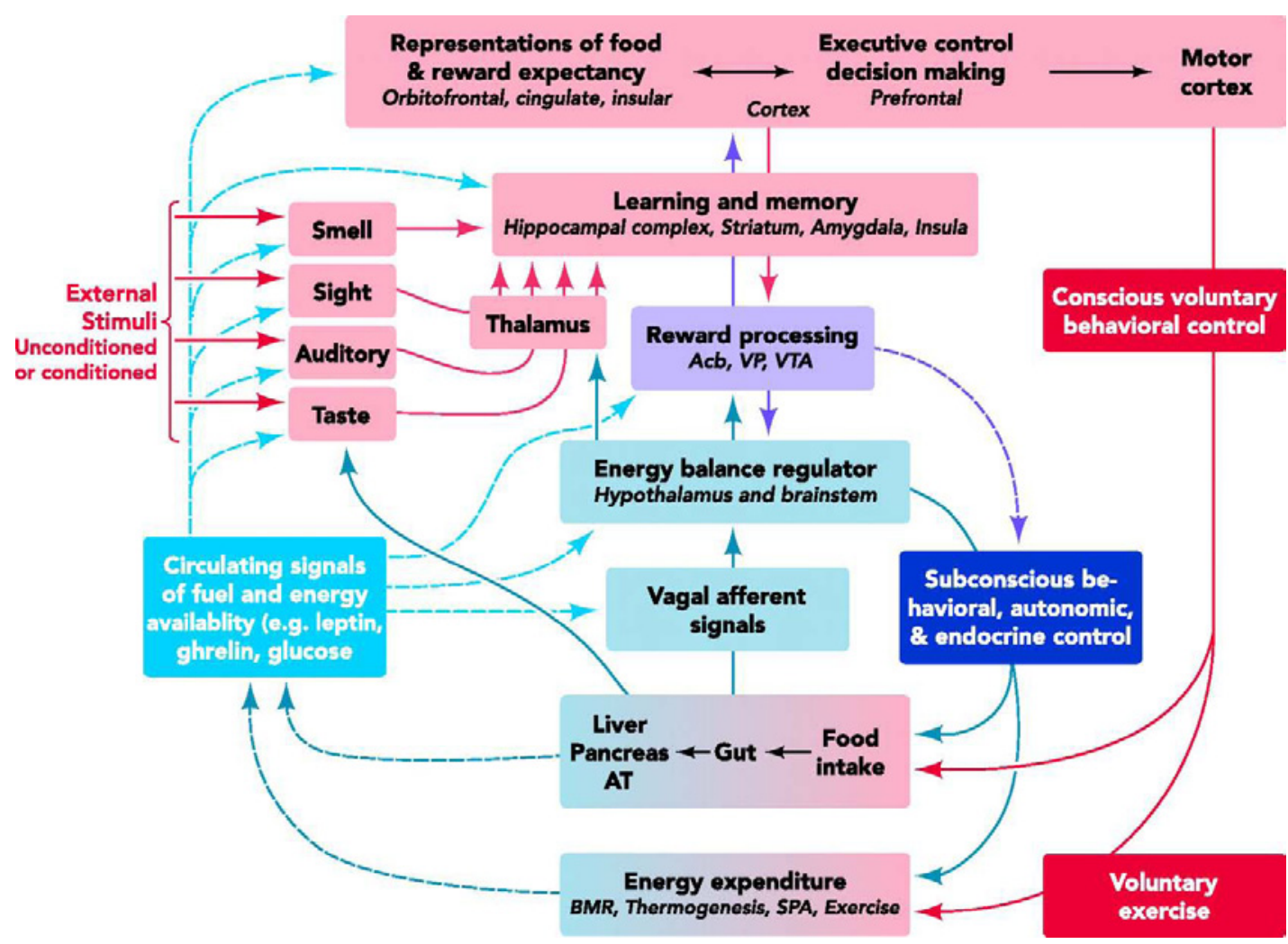

Figure 2: Courtesy with permission from Berthoud HR ref no- 134. Major Systems and pathways responsible for the neural integration of internal and external information in the control of appetite and energy expenditure

Blue areas and pathways are mainly involved in metabolic and energy balance regulation. Red areas and pathways are mainly involved in communication with the external world through cognitive and emotional processes such as learning and memory, reward, mood, stress, choice and decision making.

been submitted for registration/ waiting for, or completing phase III trials. Of these some are combinations of bupropion and naltrexone at low dose(Contrave), phentermine and topiramate(Qsymia),higher doses of existing drugs licensed for other indications(liraglutide,3mg)and new entities like lorcaserin [136]. Details of Qsymia(EQUIP/CONQUER trials)and lorcaserin [136]. Further even if these drugs get approved there are further considerations of patient's compliance, acceptability, cost, willingness to continue obesity treatment. Although definite clinical outcome benefits (atleast) have yet to be established, obesity pharmacotherapy may soon address many of the challenges in the clinical management of obesity although newer and better drug combinations and more evidence of benefit from appropriately designed outcome trials is needed [137].

Role of GLP1Agonists: One proposed model shows GLP1is released from the enter endocrine L cells in small intestine, taste receptor cells and neurons in the brain stem. The importance of central GLP1 signaling, both in glucose homeostasis as well as food intake is exemplified by (figure 3) [138].

Liraglutide: (Victoza, Nova Nordisk) is along acting GLP-1R agonist, which has $97 \%$ homology to the native GLP-1.

It was initially used for type 2 diabetes mellitus (T2DM) at doses up to $1.8 \mathrm{mg}$, after demonstrating improvements in glycemic controls in more than 4000 individuals of the Liraglutide Effect and Action in Diabetes (LEAD) programme with satisfactory tolerability [139,140]. As Liraglutide gets metabolized by dipeptidyl peptidase IV, at a much slower rate, it has a much longer duration of action than exenatide [141]. Initially Astrup, et al. in a randomized phase II dose ranging trials investigated the effects of liraglutide in 564 adults with a BMI3040KG/ M2 for 20 weeks. Participants were randomly assigned to once daily liraglutide $1.2 \mathrm{mg}, 1.8 \mathrm{mg}, 2.4 \mathrm{mg}, 2.8 \mathrm{mg}$ or $3.0 \mathrm{mg}$ (n $=95,90,93$ and 93) along with diet ( $500 \mathrm{Kcal}$ daily energy deficit) and to increase physical activity or placebo $(n=98)$ by evening $\mathrm{s} / \mathrm{c}$ injection starting at $0.6 \mathrm{mg} /$ day and increased weekly (dose escalation ). Patients lost with these doses $4.8 \mathrm{~kg}, 5.5 \mathrm{~kg}, 6.3 \mathrm{~kg}$ and $7.2 \mathrm{~kg}$ respectively, as compared to $2.8 \mathrm{~kg}$ with placebo and $4.1 \mathrm{~kg}$ with or listat. This was $2.1-4.4 \mathrm{~kg}$ greater than that with placebo and the percentage of individuals losing $>5 \%$ weight with liraglutide $3.0 \mathrm{mg}$ was $76 \%(\mathrm{n}=70)$ compared to placebo(30\%; $\mathrm{n}=29$ ) [142]. Further at 2 years, participants on liraglutide 2.4 / $3 \mathrm{mg}$ for 2 years $(\mathrm{n}=184)$ maintained a weight loss of $7.8 \mathrm{~kg}$ from time of study run in and lost $3 \mathrm{~kg}$ more weight as compared to orlistat $(\mathrm{n}=95)$. Results of SCALE (Subcutaneous Analysis of Liraglutide)-2 trials one in different doses, $1.8 \mathrm{mg}$. $3 \mathrm{mg}$ or placebo compared with 3 oral hypoglycemic agents (gov trial 
number NCT01272232) and second only with $3 \mathrm{mg}$ trial (SCALE obesity and prediabetes NN802221839-clinical trial gov no. NCT01272219 by nova nor disk) which identified the potential of liraglutide to cause weight loss as well as maintain in obese/ overweight patients without diabetes mellitus or comorbidities like hypertension, prediabetes, dyslipidemia have reported that the average weight loss for people treated with $3.0 \mathrm{mg}$ at 56 weeks was $8.0 \%$ compared with $2.6 \%$ for people treated with placebo. $5 \%$ weight loss was achieved by $64 \%$ of people treated with $3.0 \mathrm{mg}$ and $27 \%$ with placebo. While the proportion of people achieving $10 \%$ weight loss was $33 \%$ for liraglutide $3 \mathrm{mg}$ and $10 \%$ for placebo treatment [143].

Further randomized phase III trials were done by Wadden, et al. who included initial diet and exercise run in period, treatment of participants who achieved atleast 5\%weight loss during the run in $(\mathrm{n}=551, \mathrm{BMI}>30 \mathrm{Kg} / \mathrm{m} 2$ or $>27 \mathrm{~kg} / \mathrm{m} 2$ with comorbidities) with either liraglutide or placebo showed that liraglutide treatment besides maintaining weight loss achieved by lifetime interventions achieved an additional $6 \%$ weight loss over 56 weeks $(n=159)$ [144]. Similarly Kimet al found that subjects continuing to use $1.8 \mathrm{mg}$ liraglutide daily $(\mathrm{n}=24)$ lost twice the weight lost by placebo users ( $\mathrm{n}=27 ; 6.8 \mathrm{vs} 3.3 \mathrm{~kg}$; $p$ $<0.0001$ ). Besides that liraglutide users had an improvement in steady state plasma glucose concentrations as well during insulin suppression test (-3.2 vs $0.2 \mathrm{nmol} / \mathrm{l}$ and significantly greater lowering of BP, fasting glucose and triglycerides concentrations [145].

Liraglutide is generally well tolerated. Main side effect is mild to moderate nausea and vomiting which are often transient [138], but may help in achieving a greater amount of weight loss as shown in a study analyzed by Lean et al that symptomatic patients experiencing transient nausea / vomiting tended to lose $3 \mathrm{~kg}$ more weight than those who did not experience these [146]. Long term safety effects have not yet been established, as for all

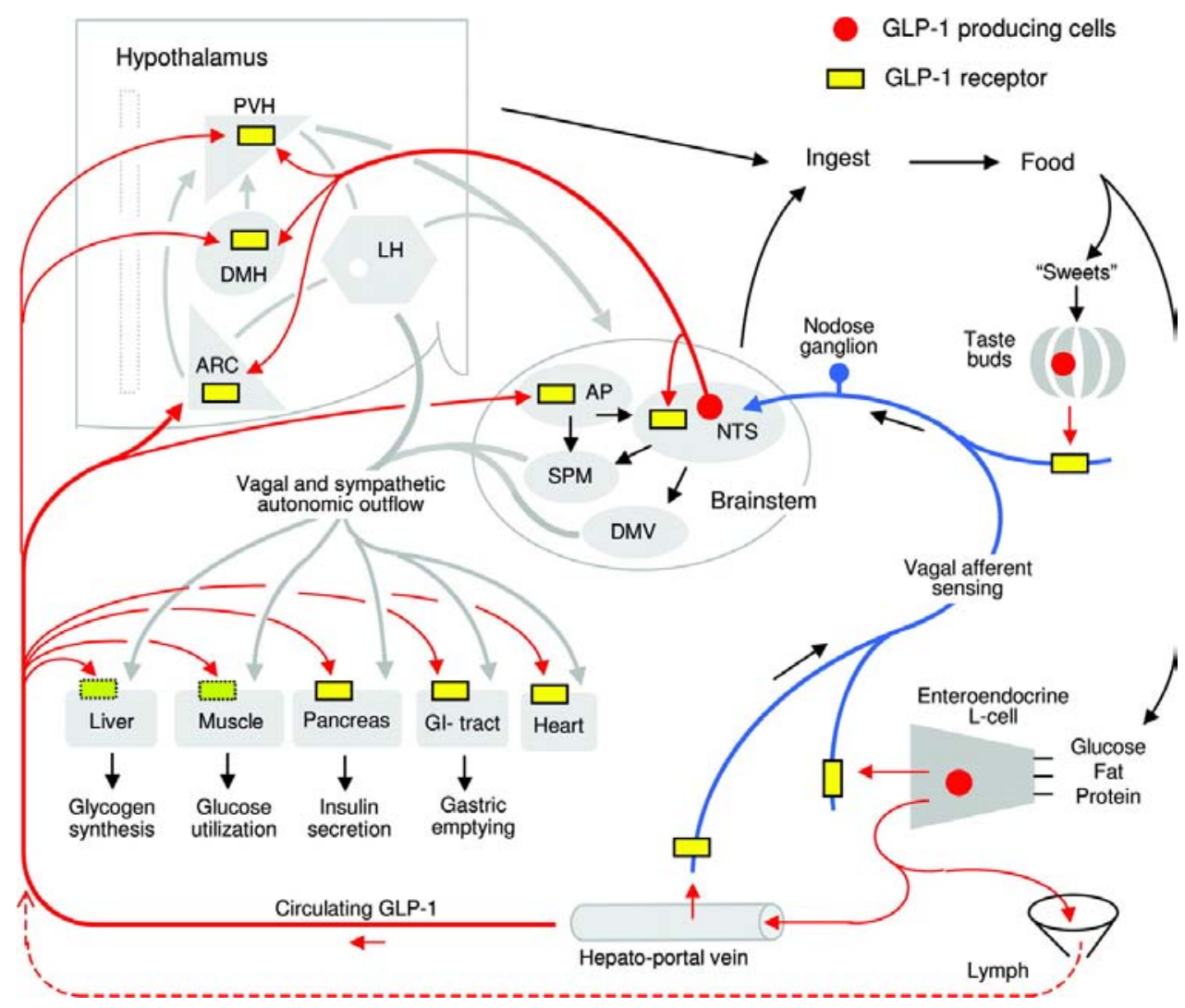

Figure 3: Courtesy ref 138 -BERTHOUD HR with Permission: GLP1 is produced and released from enteroendocrine L cells in the small intestine, taste receptor cells and neurons in the brain stem. Peripheral GLP1 is signaling via vagal and taste afferents to the nucleus of the solitary tract (NTS) in the brain stem and via the blood circulation to the stomach, pancreas, heart and brain. A different receptor may also mediate effects of circulating GLP1 on liver and muscle. Areas of the hypothalamus involved in glucose homeostasis and appetite control are differently affected by GLP1 released from NTS neuronal projections and/or circulating GLP1 freely crossing the blood brain barrier. Knauf et al have demonstrated that blockade of GLP1 signaling in the brain, but not peripherally prevents development of insulin resistance in mice fed a high fat diet. The finding suggests that nutritional abundance as during high fat feeding causes overstimulation of brain GLP1 receptors, leading to inhibition of muscle glucose uptake and hepatic glycogen synthesis through changes in autonomic outflow. The critical brain GLP1 receptor population and the involvement of brain stem GLP1expression neurons remain to be identified. AP-Area postrema; ARC, Arcuate nucleus; DMV, Dorsal motor nucleus of the vagus, DMN, Dorsal median nucleus of the hypothalamus; LH, Lateral hypothalamus; NTS, Nucleus tractus solitarius; PVH, Paraventricular nucleus of the hypothalamus; SPM, Sympathetic premotor neurons. 
GLP-1 R agonists. However the cardio protective properties of these incretins have been demonstrated both in animal models as well as humans [147]. Still concern on association between GLP-1 R agonists and pancreatitis and pancreatic cancer have been raised $[148,149]$. But since no new data had emerged the European Medical Agency (EMA) concluded in 2013 that although still some uncertainties exist with regard to pancreatic safety, no new data has emerged which implies that the risk is higher as compared to what had been previously concluded [150].

Role of X3-a mangiferin derivative: Han, et al. tried X3 -a mangiferin derivative and found it to be effective in $\mathrm{db} / \mathrm{db}$ as well as C57BL6 mice in a dose of $80 \mathrm{mg} / \mathrm{kg}$ in reducing blood glucose by activating AMPK in both LKB1 dependent and independent manner which was associated activation of downstream target of AMPK i.e. acetyl-CoA Carboxylase (ACC), in the liver, muscle and hypothalamus and was associated with an increase in number of insulin positive $\beta$-cell mass. Thus they concluded that X3 is a promising new class of AMPK activating drug, and can potentially be used in the treatment of T2DM [151].

Role of Delayed Lipolysis using novel food microencapsulation: One approach as reviewed by Corstens, et al. is developing oil/water emulsion base system which offers protection against lipase and hence offers increased satiety effect by delaying lipolysis [152].

Fucoxanthinol: is an end product of digestion of fucoxanthin from digestive enzymes in the GIT, which is obtained as a carotenoid present in the chloroplasts of brown seaweeds, which has been shown to have antiobesity effect besides anti neoplastic effect. This can be studied for strategies for developing antiobesity treatment besides its role for prevention and control of cancer as suggested by Martin L [153].

\section{Discussion and Conclusions}

Lifestyle modification like diet control, exercise, smoking cessation as exemplified by Look AHEAD(Action for Health in Diabetes) study [154] for obese diabetics remains the mainstay of weight management including,psychology aspects although only short term weight gain is achieved by this alone [155]. Prebiotics can be used as an adjunct therapy [156].

Although till date the most successive treatment has proved to be obesity surgery, one can do it only in a minority of population of obese patients and besides surgery carries its own risks although low and recently there has been a question of weight regain [157]. Hence a question for alternative therapies continues.

Although rimonabant offered to be very promising, it had to be abandoned due to marked psychiatric and suicidal side effects [reviewed in 136 and 150]. Work is in progress on $\alpha / \beta$ hydrolase domain 6 (ABDHD6) which controls 2 arachidonoyl glycerol (2-AG) levels in macrophages, oxygenation of 2-AG by Cyclooxygenase gives rise to the anti-inflammatory prostaglandin -D2-glycerol ester. Pharmacological blockade of COX2 / PGD2 synthase prevented the effects of increasing 2-AG levels by ABHD6 inhibition in vitro, as well as the 2 AG induced rise in PGD2-G levels. Together this shows the interaction of endocannabinoid system and the prostanoid systems. and thus marks ABHD6 as an interesting therapeutic target, that should be relevant in treating inflammatory conditions and PGD2-G as a bioactive lipid with potential anti-inflammatory properties [158] Some natural Ayurveda products having caralluma fimbriata extract $(500 \mathrm{mg}$ b.d) an edible succulent cacti from family Asilidae is commonly used for obesity in traditional medicine, but it did not prove to be effective in a randomized control trial [159].

The most promising pharmacological and nutritional targets at present appear to be the BAT tissue and trying to convert WAT into BAT and increase energy expenditure [160], and of these beneficial effects of carotenoid supplemental in accrual of obesity besides role of other carotenoid like products are highlighted by Lusa Bunet, et al. [161] One of the ways exercise acts is by increasing energy expenditure and does so partly by increasing the brown fat and increasing browning of white fat $[162,163]$. As shown by Seale et al the improvement in glucose tolerance may be greater than what one expects simply with browning of white fat/formation of beige on white adipocytes and their effects on weight and adiposity [164]. Recently the importance of role played by irisin was realized as it increases during exercise in rodents and partially causing browning. Fibronectin type III domain containing 5(FNDC5), its precursor protein gets synthesized as a type 1 membrane protein and then cleave and shed in blood circulation as a highly glycosylated polypeptide $(12 \mathrm{kDa})$ via viral vectors, correlating with the improvement in glucose tolerance in obese patients [165]. Zhang, et al. have shown that like $\beta$ adrenergic agonists and FGF21, irisin also signals through p38 and ERK pathway and the response occurs within 20 min following addition of irisin to the cell cultures although its receptor have not yet been identified [166]. Further on giving daily injections of irisin for over 2 weeks marked reduction in body weight was observed besides browning of AT along with improvement in glucose tolerance. A recombinant protein in yeast in form of r-irisin has already been established and this paves for the development of exercise programmes utilizing this action of irisin and further research calls for the importance for identifying irisin receptors $[167,168]$.(figure 4)

Further the role of $\mathrm{N}$-acyl phosphatidylethanolaminephospholipase D (NAPE-PLD) is exemplified by deletion of this enzyme in adipocyte, which is associated with adiposity, glucose intolerance, inflammation in AT along with lipid metabolism alterations. Deletion affects cold induced browning and the changes are caused because of shift of gut microbiota composition which can transfer the phenotype partially to germ free mice .Hence Geurits et al concluded that AT NAPE-PLD plays a role on whole body metabolism and inflammation and NAPEPLD derived bioactive lipids can be used for treating obesity and associated metabolic disorders [169].

Further strategies to exploit the role of FGF'S and FGFR seen during bariatric surgery medically is needed by developing agents having such bile acid-FGF kind of interactions.

Since cardiovascular effects are prominent even Qsymia drug regimen is not easy to use with constant heart rate monitoring 


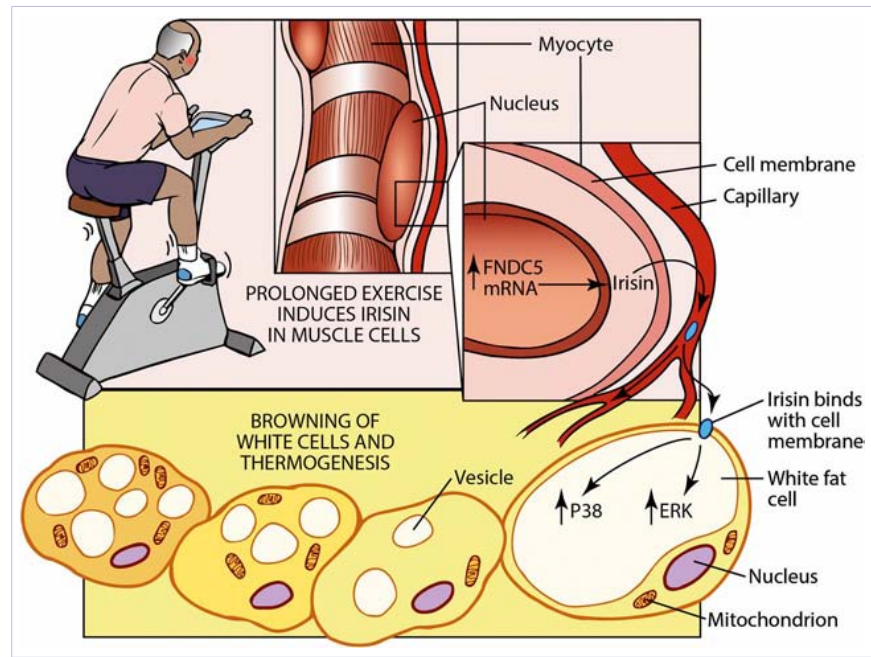

Figure 4: Courtesy ref 168 Recombinant irisin regulates the thermogenic program in fat through ERK and p38 pathways. Recombinant irisin produced in yeast is glycosylated and active. It induces the thermogenic gene program in 3T-L1 cells and primary subcutaneous adipocytes. In vitro treatment of this recombinant protein in mice show strong antiobesity effects and improve systematic glucose homeostasis.

and contraindicated in patients with cardiovascular and cerebrovascular disease and European CHMP has disallowed licensing after phase 3 trials till further safety on CVS side effects is proven .Other newer agents being developed are melanocortin type 4 receptor agonist agents targeting central hypothalamic pathway, e.g. RMP93 or peripheral metabolism e.g. beloranib increases fat oxidation.

In a National Institute of health(NIH) collaborative report it was decided that greater collaboration and crosstalk between physiological and behavioural researchers is needed to advance science and develop better strategies for weight loss maintenance [170].

\section{References}

1. WHO Obesity and overweight. Factsheet 311, 2013. http://www.who. int/mediacentre/facts sheets/fs311/en

2. Finucane MM, Stevens GA, Cowan MJ, Danaei G, Lin JK, Paciorek cj, Singh JM, et al. National, regional, and global trends in body mass index since 1980: systematic analysis of health examination surveys and epidemiological studies with 960 country-years and 9.1 million participants. Lancet. 2011;377(9765):557-67. doi: 10.1016/S01406736(10)62037-5.

3. Alm A, Fahraeus C, Wendt LK, Koch G, Andersson-Gare B, Birkhed D. Body adiposity status in teenagers and snacking adults in early childhood in relation to approximal caries at 15 years of age. Int J Paediatr Dent. 18(3):189-96.

4. Bhave S, Bavdekar A, Otiv M. IAP National TASK Force for Childhood Prevention of Adult Diseases: Childhood Obesity. Indian Pediatr. 2004;41(6):559-75.

5. Melnik BC. The potential mechanistic link between allergy and obesity development and infant formula feeding. Allergy Asthma Clin Immunol. 2014;10(1):37. doi: 10.1186/1710-1492-10-37.

6. Hata T, Murakami K, Nakatani H, Yamamoto Y, Matsuda T, Aoki N.
(2010)Isolation of bovine milk-derived microvesicles carrying mRNAs and miRNAs. Biochem Biophys Res Commun. 2010;396(2):528-33. doi: 10.1016/j.bbrc.2010.04.135.

7. Chen X, Gao C, Li H,Huang L,Sun Q,Dong Y,Tian C,Gao S,Dong H,Guan D, et al. Identification and characterization of microRNAs in raw milk during different periods of lactation, commercial fluid, and powdered milk products. Cell Res. 2010 ;20(10):1128-37. doi: 10.1038/ cr.2010.80

8. Izumi H, Kosaka N, Shimizu T, Sekine K, Ochiya T, Takase M.Bovine milk contains microRNA and messenger RNA that are stable under degradative conditions. J Dairy Sci. 2012;95(9):4831-41. doi: 10.3168/ jds.2012-5489.

9. Admyre C, Johanson SM, Qazi KR, Filen JJ, Lahesmaa R, Norman M, et al. Exosomes with immune modulatory features are present in human breast milk. J Immunol. 2007;179(3):1969-78.

10. Kosaka $\mathrm{N}$,Izumi H,Sekine $\mathrm{K}, \mathrm{Ochiya}$ T.microRNA as a new immune regulatory agent in breast milk. Silence. 2010;1(1):7. doi: 10.1186/1758-907X-1-7.

11. Sun Q,Chen X,Yu J,Zen K,Zhang CY,Li L.Immune modulatory function of abundant immune-related microRNAs in microvesicles from bovine clostrum. Protein Cell. 2013;4(3):197-210. doi: 10.1007/s13238-0132119-9.

12. Munch EM, Harris AA, Mohammad M, Benham AL, Pejerrey SM, Showalter L, HuM, Shope CD, Maningat PD, et al.(2013)Transcriptome profiling of microRNAs by next Gen deep-sequencing reveals known and novel species in the lipid fraction of human breast milk. PLoS One. 2013;8(2):e50564. doi: 10.1371/journal.pone.0050564.

13. Kohlhaas S, Garden OA, Scudamore C, Turner M, Okkenhaug K, Vigorito E.(2009)Cutting edge: the FoxP3 target miR155 contributes to the development of regulatory Tcells. J Immunol. 2009;182(5):2578-82. doi: $10.4049 /$ jimmunol.0803162.

14. Marson A, Kretschmer K, Frampton GM, Jacobsen ES, Polansky JK, MacIsaac KD, et al. Foxp3 occupancy and regulation of key target genes during T cell stimulation. Nature. 2007;445(7130):931-5.

15. Cobb BS, Hertweek A, Smith J, O'Connor E, Graf D, Cook T, et al. A role for dicer in immune regulation. J Exp Med. 2006;203(11):2519-27.

16.Zheng Y, Josefowicz SZ, KAS a, Chu TT, Gavin MA, Rudensky AY. Genome-wide analysis of FoxP3 target genes in developing and mature regulatory T cells. Nature. 2007;445(7130):936-40.

17. Landgraf K, Rockstroh D, Wagner IV, Weise S, Tauscher R, Schwartz JT, Loffler D, Buhligen U, Wojan M, et al. Evidence of early alterations in Adipose tissue biology and function and its association with obesityRelated Inflammation and Insulin Resistance in children. Diabetes. 2015;64(4):1249-61. doi: 10.2337/db14-0744.

18. CostasunaM, DiRenzo L, Sicuro L, Graiteri S, De Lorenzo A, Docimo P.Dental caries and childhood obesity: analysis of food intake and lifestyles. Eur J Paediatr Dent. 2014; 15(4):343-8.

19. Anderson DJ, Hector MP, Linden RW. The effects of unilateral and bilateral chewing, empty clenching and bruxism ,on the masticatory parotid salivary reflex in man. Exp Physiol. 1996; 81(2):305-12.

20. Atkinson JC, Wu AJ. Salivary gland dysfunction: Causes, symptoms and treatment. J Am Dent Assoc. 1994; 125(4):409-16.

21. Garrett JR, Suleiman AM, Anderson LC, Proctor GB. Secretory responses in granular ducts of acini of submandibular glands in vivo to parasympathetic or sympathetic nerve stimulation in rats. Cell Tissue Res. 1991;264(1):117-26. 
22. Aydin S, Halifeoglu I, Ozercan IH, Erman F, Kilie N, Ilhan N, Ozkan Y, et al. Acomparison of leptin and ghrelin levels in plasma and saliva of young healthy subjects. Peptides. 2005;26(4):647-52.

23. Matsuo R, Shimizu N, Kusano K. Lateral hypothalamic modulations of oral sensory afferent activity in nucleus tractus solitaries neurons of rats. J Neurosci. 1984;4(5):1201-7.

24. Matsuo R, Kusano K. Lateral hypothalamic modulation of the gustatory-salivary reflex in rats. J Neurosci. 1984; 4(5):1208-16.

25. Ueda H, Amitani H, Asakawa A, Ikeda S, Miyawaki S, Inui A. The role of salivary secretion, brain -gut peptides, and oral hygiene in obesity. Obes Res Clin Pract. 2013;7(5):e321-9.

26. Omar OM, Metwali NE, Elsedfy ZB, Abbas AH. Lifestyle and body mass index, implications for oral health in a group of Egyptian children. Cairo Dent J Part (II); 183:192.

27. Hilgers KK, Akridge M, Scheetz JP, Kinane DE. Childhood obesity and dental development. Pediatr Dent. 2006; 28(1):18-22.

28.Johnson BC, Lincoln NE. New Prescriptions for Childhood Obesity: Fight Childhood Obesity with Antioxidants \& Phytonutrients. I Universe. 2008.

29.Gunjalli G, Kumar KN, Jain SK, Reddy SK, Shavi GR, Ajaganananavar SL.Total salivary antioxidant levels, dental development $t$ and oral health status in childhood obesity. J Int Oral Health. 2014;6(4):63-7.

30. Son YH, Ka S, Kim AY, Kim JB. Regulation of Adipocyte differentiation via MicroRNAs. Endocrinol Metab (Seoul). 2014;29(2):122-35. doi: 10.3803/EnM.2014.29.2.122.

31. Cipolelletta D, Feurer M, Nozomu Kamei AL, Lee J, Shoelson SE, Benoist C, Mathis D(2012).PPAR- $\gamma$ is a major driver of the accumulation and phenotype of adipose tissue Treg cells. Nature. 2012;486(7404):54953. doi: $10.1038 /$ nature 11132 .

32.Cannon B, Nedergaard J.Brown adipose tissue: function and physiological significance. Physiol Rev. 2004 ;84(1):277-359.

33. Lonear D, Afzelius BA, Cannon B. Epididymal white adipose tissue after cold stress in rats. L Nonmitichondrial changes. J Ultrastruct Mol Struct Res. 1988;101(2-3):109-22.

34.Walden TB,Hansen IR,Timmons JA,Cannon B,Nedergaard J.(2012) Recruited vs. nonrecruited molexular signatures of brown,"brite"and white adipose tissues. Am J Physiol Endocrinol Metab. 2012;302(1):E19-31. doi: 10.1152/ajpendo.00249.2011.

35.Petrovic N, Walden TB, Shabalina IG, TimmonsJA,Cannon B, Nedergaard J. Chronic Peroxisome Proliferator-activated receptor gamma(PPAR gamma)activation of epididymally derived white adipocyte cultures reveals a population of thermogenically competent,UCP1-containing adipocytes molecularly distinct from classic brown adipocytes. J Biol Chem. 2010;285(10):7153-64. doi: 10.1074/jbc.M109.053942.

36.Pisani DF, Djedaini M. Beranger GE, Elabd C, Scheideler M, et al. Differentiation of human adipose -derived stem cells into "brite"(brown in white)adipocytes. Front Endocrinol (Lausanne). 2011;2:87. doi: 10.3389/fendo.2011.00087.

37.Wu J, Bostrom P, Sparks LM, Ye L, Choi JH, et al. Beige adipocytes are a distinct type of thermogenic fat cell in mouse and human . Cell. 2012;150(2):366-76. doi: 10.1016/j.cell.2012.05.016.

38. Feidmann HM, Golozoubova V, Cannon B,Nedergaard J.(2009)UCP1 ablation induces obesity and abolishes diet induced thermogenesis in mice exempt from thermal stress by living at thermoneutrality. Cell Metab. 2009; 9(2):203-9. doi: 10.1016/j.cmet.2008.12.014.
39. Rothwell NJ, Stock MJ. Luxuskonsumption, diet induced thermogenesis and brown fat: the case in favour. Clin Sci (Lond). 1983;64(1):19-23.

40. Nedergaard J, Cannon B. (2010) The changed metabolic world with human brown adipose tissue: therapeutic visions. Cell Metab. 2010;11(4):268-72. doi: 10.1016/j.cmet.2010.03.007.

41. Karbeiner M, Schneider M. MicroRNA Functions in Brite/Brown FatNovel perspectives towards antiobesity strategies. Comput Struct Biotechnol J. 2014;11(19):101-5. doi: 10.1016/j.csbj.2014.09.005.

42. Dawkins MJ, Scopes JW. Nonshivering thermogenesis and brown adipose tissue in the new born infant. Nature 206, 201 - 202; doi: $10.1038 / 206201 \mathrm{~b} 0$

43. Nedergaard J, Bengtsson T, Cannon B. Unexpected evidence of active brown adipose tissue in adult humans. Am J Physiol Endocrinol Metab. 2007; 93(2):E444-52.

44. Cypess AM, Lehman S, Williams G, Tal I, Rodman D, et al. Identification and importance of brown adipose tissue in adult humans. $\mathrm{N}$ Engl J Med. 2009;360(15):1509-17. doi: 10.1056/NEJMoa0810780.

45.van Marken Lichtenbelt WD, Vanhommerig JW, Smulders NM, Drossaerts JM, Kemerink GJ, Bouvy ND, et al. Cold-activated brown adipose tissue in healthy men. N Engl J Med. 2009;360(15):1500-8. doi: 10.1056/NEJMoa0808718.

46. Virtanen KA, Lidell ME, Orava J, Heglind M, Westergren R , et al. Functional brown adipose tissue in healthy adults. N Engl J Med. 2009; 360(15):1518-25. doi: 10.1056/NEJMoa0808949.

47. Atit R, Sgaier SK, Mohamed OA, Taketo MM, Dufort D, Joyner AL, et al. Beta-catenin activation is necessary and sufficient to specify the dorsal dermal fate in the mouse. Dev Biol. 2006; 296(1):164-76.

48. Timmons JA, Wennmalm K, Larsson $\mathrm{O}$, Walden TB, Lassmann $\mathrm{T}$, Petrovic N, et al. Myogenic gene expression signature establishes that brown and white adipocytes originate from distinct cell lineages. Proc Natl Acad Sci U S A. 2007; 104(11):4401-6.

49. Seale P, Bjork B, Yang W, Kajimura S, Chin S, Kuang S, et al. PRDM 16 controls a brown fat/skeletal muscle switch. Nature. 2008 ;454(7207):961-7. doi: 10.1038/nature07182.

50. Ussar S, Lee KY, Dankel SN, Boucher J, Haering MF, Kleinridders A, et al.(2014).Asc1-PAT2,P2RX5 are cell surface markers for white, beige/ brite and brown adipocytes. Sci Transl Med. 2014;6(247):247ra103. doi: 10.1126/scitranslmed.3008490.

51. Bordicchia M, Liu D, Amri EZ, Ailhaud G, Dessi-Fulgheri P, et al.Cardiac natriuretic peptides act via p38 MAPK to induce the brown fat thermogenesis program in mouse and human adipocytes. J Clin Invest. 2012;122(3):1022-36. doi: 10.1172/JCI59701.

52. Bonet ML, Oliver PL, Palou A. Pharmacological and nutritional agents promoting browning of white adipose tissue. Biochim Biophys Acta. 2013;1831(5):969-85. doi: 10.1016/j.bbalip.2012.12.002.

53. Diaz MB, Herzig S, Vegiopoulos A. Thermogenic adipocytes: from cells to physiology and medicine. Metabolism. 2014 ;63(10):1238-49. doi: 10.1016/j.metabol.2014.07.002.

54. Fu J, Li Z, Zhang H, Mao Y, Wang A, Wang X, et al. Molecular pathways regulating the formation of brown like adipocytes in white adipose tissue. Diabetes Metab Res Rev. 2015;31(5):433-52. doi: 10.1002/ dmrr.2600.

55. Hondares E, Gallego-EscuredoJM, Flachs P, Frontini A, Cereijo R, Goday A, et al. Fibroblast growth factor 21 is expressed in neonatal and pheochromocytoma- induced adult human brown adipose tissue. Metabolism. 2014; 63(3):312-7. doi: 10.1016/j.metabol.2013.11.014. 
56. Lee P, Linderman JD, Smith S, Brychta RJ, Wang J, Idelson C, et al. Irisin and FGF21 are cold blooded endocrine activators of brown fat function in humans. Cell Metab. 2014;19(2):302-9. doi: 10.1016/j. cmet.2013.12.017.

57.Fisher FM, Kleiner S, Douris N, Fox EC, Mepani RJ, Verdeguer F, et al.FGF21 regulates PGC1 $\alpha$ and browning of white adipose tissue in adaptive thermogenesis. Genes Dev. 2012; 26(3):271-81. doi: 10.1101/gad.177857.111.

58. Moro C, Lafontan M. (2013).Natriuretic peptides and cGMP signaling control of energy homeostasis. Am J Physiol Heart Circ Physiol. 2013;304(3):H358-68. doi: 10.1152/ajpheart.00704.2012.

59. Collins S. A heart-adipose tissue connection in the regulation of energy metabolism. Nat Rev Endocrinol. 2014; 10(3):157-63. doi: 10.1038/ nrendo.2013.234.

60.Tseng YH, Kokkotou E, Schulz TJ, Huang TL, Winnay JN, Taniguchi CM, et al.(2008).New role of bone morphogenetic protein 7 in brown adipogenesis and energy expenditure. Nature. 2008;454(7207):10004. doi: 10.1038 /nature 07221 .

61. Whittle AJ, Carobbio S, Martins L, Slawik M, Hondares E, Vázquez MJ, et al. BMP8B increases brown adipose tissue thermogenesis through both central and peripheral actions. Cell. 2012;149(4):871-85. doi: 10.1016/j.cell.2012.02.066.

62.Sellayah D, Bharaj P, Sikder D. Orexin is required for brown adipose tissue development, differentiation and function. Cell Metab. 2011;14(4):478-90. doi: 10.1016/j.cmet.2011.08.010.

63.Ahfeldt T, Schinzel RT, Lee YK, Hendrickson D, Kaplan A. et al Programming human pluripotent stem cells into white and brown adipocytes. Nat Cell Biol; 14:209-219.

64.Kong X, Banks A, Liu T, Kazak L, Rao RR, Cohen P, et al.(2014) IRF4 is a key thermogenic transcriptional partner of PGC- $1 \alpha$. Cell. 2014;158(1):69-83. doi: 10.1016/j.cell.2014.04.049.

65. Ma X, Lee P, Chisholm DJ, James DE. Control of adipocyte differentiation in different fat depots ;implications for pathophysiology or therapy. Front Endocrinol (Lausanne). 2015;6:1. doi: 10.3389/ fendo.2015.00001.

66.Ortega FJ, Mayas D, Moreno-Navarelle JM, Bassols J, Rodriques Hermosa J, et al. The gene expression of the main lipogenic enzymes is down regulated in visceral adipose tissue of obese subjects. Obesity (Silver Spring). 2010;18:13-20

67. Yahagi N, Shimano H, Hasty AH ,Matsuzaka T, Ide T, et al. Absence of sterol regulatory element-binding protein-1 (SREBP-1) ameliorates fatty livers but not obesity or insulin resistance in Lep (ob)/Lep(ob) mice. J Biol Chem. 2002 May; 277(22):19353-7.

68.Sekiya M, Yahagi N, Matsuzaka T, Takeuchi Y, Nakagawa Y, et al.SREBP-1 independent regulation of lipogenic gene expression in adipocytes. J Lipid Res. 2007; 48(7):1581-91

69. Ortega FJ, Moreno-Navarrete JM, Mayas D, Garcia-Santos E, Serrano GM, Rodriquez-Hermosa JI.et al. Breast Cancer 1(BrCa1)may be behind decreased lipogenesis in adipose tissue from obese subjects. PLoS One. 2012;7(5):e33233. doi: 10.1371/journal.pone.0033233.

70. Moreno-Navarrete JM, Moreno M, Ortega F, Serrano M, Xifra G, Ricart $\mathrm{W}$, et al. Deleted in breast cancer1 plays a functional role in adipocyte differentiation. Am J Physiol Endocrinol Metab. 2015;308(7):E554-61. doi: 10.1152/ajpendo.00286.2014.

71. Romeo GR, Lee J, Shoelson SE. Metabolic syndrome, insulin resistance and roles of inflammation-mechanisms and therapeutic targets.
Arterioscler Thromb Vasc Biol. 2012;32(8):1771-6. doi: 10.1161/ ATVBAHA.111.241869.

72. Odegaard JL, Chawla A. (2013) Pleiotropic actions of insulin resistance and inflammation in metabolic homeostasis. Science. 2013;339(6116):172-7. doi: 10.1126/science.1230721

73. Lee BC, Lee J,(2014).Cellular and molecular players in adipose tissue inflammation in the development of obesity induced insulin resistance. Biochim Biophys Acta. 2014;1842(3):446-62. doi: 10.1016/j.bbadis.2013.05.017.

74. Mathis D, Shoelson SE. Immunometabolism: an emerging frontier. Nat Rev Immunol. 2011;11(2):81. doi: 10.1038/nri2922.

75. Mraz M, Haluzik M. The role of adipose tissue immune cells in obesity and low grade inflammation. J Endocrinol. 2014;222(3):R113-27. doi: 10.1530/JOE-14-0283.

76. Cani PD, Amar J, Iglesias MA, Poggi M, Knauf C, Bastelica D, et al. Metabolic endotoxemia initiates obesity and insulin resistance. Diabetes. 2007;56(7):1761-72.

77.Cani PD, Bibiloni R, Knauf C, Waget A, Neyrinck AM, Delzenne NM, et al. Changes in gut microbiota control metabolic endotoxemia induced inflammation in high -fat diet induced obesity and diabetes in mice. Diabetes. 2008; 57(6):1470-81. doi: 10.2337/db07-1403.

78. Turnbaugh PJ, Ley RE, Mahowald MA, Magrini V, Mardis ER, Gordon JI . An obesity assoiated gut microbiome with increased capacity for energy harvest. Nature; 444:1027-31.

79. Burcelin R, Serino M, Chabo C, Garidou L, Pomie Courtney M, Amar J, Bouloumio A. Metagenome and metabolism: the tissue microbiota hypothesis. Diabetes Obes Metab. 2013;15 Suppl 3:61-70. doi: 10.1111/dom.12157.

80. Carvalho BM, Saad MJ. Influence of Gut microbiota on subclinical inflammation and insulin resistance .Mediators Inflamm; 2013:986734.

81. Kim S, Kim JH, Park BC, Kwak YS. Perspectives on the therapeutic potential of short chain fatty acid receptors. BMB Rep. 2014;47 (3):1738.

82. Meijer K, de Vos P, Priebe MG. Butyrate and other short chain fatty acid modulators of immunity: what relevance for health? Curr Opin Clin Nutr Metab Care. 2010;13(6):715-21. doi: 10.1097/ MCO.0b013e32833eebe5.

83. Al-Lahham S, Roelofsen H, Rezaee F, Weening D, Hoek A, Vonk R, Venema K. Propionic acid affects immune status and metabolism in adipose tissue from overweight subjects. Eur J Clin Invest. 2012;42(4):357-64. doi: 10.1111/j.1365-2362.2011.02590.x.

84. Adolph TE, Tomczak MF, Niederreiter L, Ko HJ, Böck J, Martinez-Naves $\mathrm{E}$, et al. Paneth cells as a site of origin of intestinal inflammation. Nature. 2013;503(7475):272-6. doi: 10.1038/nature12599.

85. Rosenstiel P.(2013).Stories of love and hate: innate immunity and host microbe crosstalk in the intestine. Curr Opin Gastroenterol. 2013;29(2):125-32. doi: 10.1097/MOG.0b013e32835da2c7.

86. Everard A, Geurts L, Caesar R, Van Hul M, Matamoros S, Duparc T, et al. Intestinal MyD88 is a sensor switching host metabolism towards obesity according to nutritional status. Nat Commun. 2014;5:5648. doi: $10.1038 /$ ncomms 6648 .

87. Krinninger P, Ensenauer R, Ehlers $\mathrm{K}$ et al. Peripheral monocytes of obese women display increased chemokine receptor expression and migration capacity. J Clin Endocrinol Metab.2014;99(7):2500-9. doi: 10.1210/jc.2013-2611. 
88. Hilgendorf I, Swirski FK. Making a difference: monocyte heterogeneity in cardiovascular disease. Curr Atheroscler Rep. 2012;14(5):450-9. doi: $10.1007 / \mathrm{s} 11883-012-0274-8$.

89. Poitou C,DalmasE, Renovato M, etal.(2011)CD14dimCD16+monocytes and $\mathrm{CD} 14+\mathrm{CD} 16+$ monocytes in obesity and during weight loss: relationship with fat mass and subclinical atherosclerosis. Arterioscler Thromb Vasc Biol. 2011;31(10):2322-30. doi: 10.1161/ ATVBAHA.111.230979.

90.Yvan-Charvet L, Quignard-Boulange A. Role of adipose tissue reninangiotensin system in metabolic and inflammatory disease associated with obesity. Kidney Int. 2011;79(2):162-8. doi: 10.1038/ki.2010.391.

91. Mathai MI, Chen N, Cornall L, Weisinger RS. The role of angiotensin in obesity and metabolic disease. Endocr Metab Immune Disord Drug Targets. 2011;11(3):198-205.

92.Goossene GH, Blaak EE, van Baak MA. Possible involvement of the adipose tissue renin-angiotensin system in the pathophysiology of obesity and obesity related disorders. Obes Rev. 2003;4(1):43-55.

93. Porter JP, Anderson JM, Robison RJ, Phillips AC. Effects of central angiotensin II on body weight gain in young rats. Brain Res. 2003;959(1):20-8.

94.Porter JP, Potratz KR. Effect of intracerebroventricular angiotensin II on body weight and food intake in adult rats. Am J Physiol Regul Integr Comp Physiol. 2004;287(2):R422-8.

95.Grobe JL, Grobe CL, Beltz TG, Westphal SG, Morgan DA, Xu D, et al. The brain renin angiotensin system controls divergent efferent mechanisms to regulate fluid and energy balance. Cell Metab. 2010;12(5):431-42. doi: 10.1016/j.cmet.2010.09.011.

96.Cassis LA, English VL, Bharadwaj K, Boustany CM. (2004) Differential effects of local versus systemic angiotensin II in the regulation of leptin release from adipocytes. Endocrinology. 2004;145(1):169-74.

97. Hilzendeger AM, Morais RL, Todiras M, Plehm R, da Costa Goncalves A, Qadri F, et al. Leptin regulates ACE activity in mice. J Mol Med (Berl). 2010;88(9):899-907. doi: 10.1007/s00109-010-0649-7.

98.Smith PM, Chambers AP, Price CJ, Ho W, Hopf C, Sharkey KA et al. The subfornical organ: a central nervous system site for actions of circulating leptin. Am J Physiol Regul Integr Comp Physiol. 2009;296(3):R512-20. doi: 10.1152/ajpregu.90858.2008.

99. Young CN, Morgan DA, Butler SD, Mark AL, Davisson RL. The brain subfornical organ mediates leptin induced increases in sympathetic activity but not its metabolic effects. Hypertension. 2013;61(3):73744. doi: 10.1161/HYPERTENSIONAHA.111.00405.

100. Arakawa H, Chitravanshi VC, Sapru HN. The hypothalamic arcuate nucleus; a new site of cardiovascular action of angiotensin(1-12) and angiotensin II. Am J Physiol Heart Circ Physiol. 2011;300(3):H951-60. doi: 10.1152/ajpheart.01144.2010.

101. McKinley MJ1, Allen AM, Clevers J, Paxinos G, Mendelsohn FA. Angiotensin receptor binding in human hypothalamus: autoradiographic localization. Brain Res. 1987;420(2):375-9.

102.Hayes MR, Skibicka KP, Leichner TM, GuarnieriDJ, Di Leone RJ, Bence $\mathrm{KK}$, et al. Endogenous leptin signaling in the caudal nucleus tractus solitarius and area postrema is required for energy balance regulation. Cell Metab. 2010;11(1):77-83. doi: 10.1016/j.cmet.2009.10.009.

103.Benarroch EE, Schmeichel AM. Immunohistochemical localization of the angiotensin II type I receptor in human hypothalamus and brainstem. Brain Res. 1998;812(1-2):292-6.

104.Gonzalez AD, Wang G, Waters EM, Gonzales KL, Speth RC, Van
Kempen TA, et al. Distribution of angiotensin type 1a receptorscontaining cells in the brains of bacterial artificial chromosome transgenic mice. Neuroscience. 2012;226:489-509. doi: 10.1016/j. neuroscience.2012.08.039.

105.Hilzendeger AM, Morgan DA, Brooks L, Dellsperger D, Liu X, Grobe $\mathrm{JL}$, et al. A brain leptin renin angiotensin system interaction in the regulation of sympathetic nerve activity. Am J Physiol Heart Circ Physiol. 2012;303(2):H197-206. doi: 10.1152/ajpheart.00974.2011.

106.Cottrell GT, Ferquson AV. Sensory circumventricular organs: central roles in the integrated autonomic regulation. Regul Pept. 2004;117(1):11-23.

107.Ferguson AV. Angiotensinergic regulation of autonomic and neuroendocrine inputs: Central sites for the subfornical organ and the paraventricular nucleus. Neuroendocriniology. 89(4):370-6.

108.Mimee A, Smith PM, Ferquson AV. Circumventricular organs: targets for integration of circulating fluid and energy balance signals? Physiol Behav. 2013;121:96-102. doi: 10.1016/j.physbeh.2013.02.012.

109.Young CN, Morgan DA, Butler SD, Mark AL, Davisson RL, et al. Angiotensin type $1 \mathrm{a}$ receptors in the forebrain subfornical organ facilitates leptin induced weight loss through brown adipose tissue thermogenesis. Mol Metab. 2015;4(4):337-43. doi: 10.1016/j. molmet.2015.01.007.

110.Furuahashi M, Mita T, Moniwa N, Hoshina K, Ishimura S, Fuseya T, et al. Angiotensin II receptor blockers decrease serum concentration of fatty acid binding protein 4 in patients with hypertension. Hypertens Res. 2015;38(4):252-9. doi: 10.1038/hr.2015.2.

111.Moulle VS, LeFoll C, Philippe E, Kassis N, Rouch C, Marsollier N, et al. Fatty Acid transporter CD36 Mediates hypothalamic effects of fatty acids on food intake in rats. PLoS One. 2013;8(9):e74021. doi: 10.1371/journal.pone.0074021.

112.Jiao H, Arner P, Dickson SL, Vidal H, Mejhert N, et al. Genetic association and gene expression analysis identify FGFR1 as a new susceptibility gene for human obesity. J Clin Endocrinol Metab. 2011;96(6):E962-6. doi: 10.1210/jc.2010-2639.

113.Beenken A, Mohammadi M. The FGF family: biology, pathophysiology and therapy. Nat Rev Drug Discov. 2009;8(3):235-53. doi: 10.1038/ $\operatorname{nrd} 2792$.

114.Itoh N, Ornitz DM. Fibroblast growth factors: from molecular evolution to roles in development, metabolism and disease. J Biochem. 2011;149(2):121-30. doi: 10.1093/jb/mvq121.

115.Sun HD, Malabunga M, Tonra JR, DiRenzo R, Carrick FE, et al. Monoclonal antibody antagonists of hypothalamic FGFR1 cause potent but reversible hypophagia and weight loss in rodents and monkeys. Am J Physiol Endocrinol Metab. 2007;292(3):E964-76.

116.Wu AL, Kolumam G, Stawicki S, Chen Y, Li J et al. Amelioration of type2 diabetes by antibody -mediated by activation of fibroblast growth factor receptor1. Sci Transl Med. 2011;3(113):113ra126. doi: 10.1126/scitranslmed.3002669.

117.Lelliott CL, Ahnmark A, Admyre T, Ahlstedt T, Irving L, Keyes K, et al. Monoclonal Antibody targeting of fibroblast growth factor receptor $1 \mathrm{c}$ ameliorates obesity and glucose intolerance via central mechanisms. PLoS One. 2014;9(11):e112109. doi: 10.1371/journal. pone.0112109.

118.Locke AE, Kahali B, Berndt SI, Justice AE, Pers TH, Day FR, et al. Genetic studies of body mass index yield new insights for obesity biology . Nature. 2015;518(7538):197-206. doi: 10.1038/nature14177. 
119.Shin AC, Berthoud HR. Obesity surgery: happy with less or eternally hungry? Trends Endocrinol Metab. 2013;24(2):101-8. doi: 10.1016/j. tem.2012.11.009.

120.Jansen PL1, van Werven J, Aarts E, Berends F, Janssen I, Stoker J, et al. Alterations of hormonally active fibroblast growth factors after Roux-en Y gastric bypass surgery. Dig Dis. 2011;29(1):48-51. doi: 10.1159/000324128.

121.Pournaras DJ, Glicksman C, Vincent RP, Kuganolipava S, AlaghbandZadeh J, Mahon D, et al. The role of bile after Roux-en Y gastric bypass in promoting weight loss and improving glycaemic control. Endocrinology. 2012;153(8):3613-9. doi: 10.1210/en.2011-2145

122.Simonen M, Dali-Youcef N, Kaminska D, Venesmaa S, Käkelä $\mathrm{P}$, Pääkkönen $\mathrm{M}$, et al. Conjugated bile acids associate with altered rates of glucose and lipid oxidation after Roux-en Y Gastric Bypass. Obes Surg. 2012;22(9):1473-80. doi: 10.1007/s11695-012-0673-5.

123.Cummings BP, Bettaieb A, Graham JL, Stanhope KL, Kowala M, Haj FG, et al. Vertical sleeve gastrectomy improves glucose and lipid metabolism and delays diabetes onset in UCD -T2DM rats. Endocrinology; 153:3620-3632.

124.Porez G, Prawitt J, Gross B, Staels B. Bile acid receptors as targets for the treatment of dyslipidemia and cardiovascular disease. J Lipid Res. 2012;53(9):1723-37. doi: 10.1194/jlr.R024794.

125.Keitel V, Görg B, Bidmon HJ, Zemtsova I, Spomer L, Zilles K, et al. The bile acid receptor TGR5 (Gpbar1) acts as a neurosteroid receptor in brain. Glia. 2010;58(15):1794-805. doi: 10.1002/glia.21049.

126.Castro-Caldas M, Carvalho AN, Rodrigues E, Henderson CJ, Wolf CR, Rodrigues CM, et al. Tauroursodeoxycholic acid prevents MPTPinduced dopaminergic cell death in a mouse model of Parkinson's disease. Mol Neurobiol. 2012;46(2):475-86. doi: 10.1007/s12035012-8295-4.

127.Schubring SR, Fleischer W, Lin JS, Haas HL, Sergeeva OA. The bile steroid chenodeoxycholate is a potent antagonist at NMDA and GABA (A) receptors. Neurosci Lett. 2012;506(2):322-6. doi: 10.1016/j. neulet.2011.11.036.

128.0zcan L, Ergin AS, Lu A, Chung J, Sarkar S, Nie D, et al. Endoplasmic reticulum stress plays a central role in development of leptin resistance. Cell Metab. 2009;9(1):35-51. doi: 10.1016/j. cmet.2008.12.004.

129.Sarruf DA1, Thaler JP, Morton GJ, German J, Fischer JD, Ogimoto $\mathrm{K}$, et al. Fibroblast growth factor 21 action in the brain increases energy expenditure and insulin sensitivity in obese rats. Diabetes. 2010;59(7):1817-24. doi: 10.2337/db09-1878.

130.Kralisch S, Fasshauer M. Fibroblast growth factor 21: effects on carbohydrate and lipid metabolism in health and disease. Curr Opin Clin Nutr Metab Care. 2011;14(4):354-9. doi: 10.1097/ MCO.0b013e328346a326.

131.Watanabe M, Houten SM, Mataki C, Christoffolete MA, Kim BW, Sato H, et al. Bile acids induce energy expenditure by promoting intracellular thyroid hormone activation. Nature. 2006;439(7075):484-9.

132.Thomas C, Gioiello A, Noriega L, Strehle A, Oury J, Rizzo G, et al. TGR5mediated bile acid sensing controls glucose homeostasis. Cell Metab. 2009;10(3):167-77. doi: 10.1016/j.cmet.2009.08.001.

133.Berridge KC, Robinson TE, Aldridge JW. Dissecting components of reward: 'liking', 'wanting' and learning. Curr Opin Pharmacol. 2009;9(1):65-73. doi: 10.1016/j.coph.2008.12.014.

134.Zheng H, Berthoud HR. Neural systems controlling the drive to eat: mind versus metabolism. Physiology (Bethesda). 2008;23:75-83. doi: 10.1152/physiol.00047.2007.

135.Kumar N (2015).Endoscopic therapy for weight loss: Gastroplasty, duodenal sleeves, intragastric balloons, and aspiration. World J Gastrointest Endosc. 2015;7(9):847-59. doi: 10.4253/wjge.v7.i9.847.

136.Kochar Kaur K, Allahbadia GN, Singh M. Current management of obesity in infertile female: Recent Advances and future Prospective drugs. J Pharmacy Nutr Sci. 2013;3(3):1-13.

137.Pucci A, Finer N. New medications for treatment of obesity: Metabolic and cardiovascular effects. Can J Cardiol. 2015;31(2):142-52. doi: 10.1016/j.cjca.2014.11.010.

138.Berthoud HR (2008). Paying the price for eating ice cream: is excessive GLP1 signaling in the Brain the culprit? Endocrinology. 2008;149(10):4765-7. doi: 10.1210/en.2008-0932.

139.Garber A, Henry R, Ratner R, Garcia-Hernandez PA, Rodriguez-Patzi $\mathrm{H}$, Oliver-Alvarez I, et al .Liraglutide versus glimepiride monotherapy for type 2 diabetes(LEAD-3 Mono)a randomized 52 weeks, phase III ,double blind ,parallel treatment trial. Lancet. 2009;373(9662):47381. doi: 10.1016/S0140-6736(08)61246-5.

140.Vilsboll T, Zdravkovic M, Le Thi T, Krarup T, Schmitz O, Courreges JP, et al. Liraglutide ,a long acting human glucagon like peptide- 1 analog, given as monotherapy significantly improves glycaemic control and lowers body weight without risk of hypoglycemia in patients with type 2 diabetes. Diabetes Care. 2007;30(6):1608-10.

141.Malm-Erjefalt M, Bjornsdottir I, Vanggaard J, Helleberg H, Larsen U, Oosterhuis B, et al. Metabolism and excretion of the once daily human glucagon like peptide-1 analog liraglutide in healthy male subjects and in vitro degradation by dipeptidyl peptidase IV and neutral endopeptidase. Drug Metab Dispos. 2010;38:1944-1953.

142.Astrup A, Rossner S, Van-Gaal L, Rissanen A, Niskanen L, Al Hakim M, et al. Effects of liraglutide in the treatment of obesity: a randomized, double blind, placebo controlled study. Lancet. 2009;374(9701):1606-16. doi: 10.1016/S0140-6736(09)61375-1.

143.Astrup A, Carraro R, Finer N, Harper A, Kunesova M, Lean ME, et al. Safety, tolerability and sustained weight loss over 2 years with the once daily human GLP-1 analog liraglutide. Int J Obes (Lond). 2012;36(6):843-54. doi: 10.1038/ijo.2011.158.

144.Wadden TA, Hollander P, Klein S, Niswender K, Woo V, Hale PM, et al. Weight maintenance and additional weight loss with liraglutide after low calorie diet induced weight loss :the scale maintenance randomized study. Int J Obes (Lond). 2013;37(11):1443-51. doi: 10.1038/ijo.2013.120.

145.Kim S, Abbasi F, Lamendola C, Liu A, Ariel D, Schaaf P, et al. Benefits of liraglutide treatment in overweight and obese older individuals with prediabetes. Diabetes Care. 2013;36(10):3276-82. doi: 10.2337/ dc13-0354.

146.Lean ME, Carraro R, Finer N, Hartvig H, Lindegaard M, Rossner S, et al. Tolerability of nausea and vomiting, and associations with weight loss, in randomized trial of liraglutide in obese, non-diabetic adults. Int J Obes (Lond). 2014;38(5):689-97. doi: 10.1038/ijo.2013.149.

147.Ussher JR, Drucker DJ. Cardiovascular biology of the incretin system. Endocr Rev. 2012;33(2):187-215. doi: 10.1210/er.2011-1052.

148.Butler PC, Elashoff M, Elashoff R, Gale E. A critical analysis of the clinical use of incretin based therapies: Are the GLP1 therapies safe? Diabetes Care. 2013;36(7):2118-25. doi: 10.2337/dc12-2713.

149.Cohen D. Has pancreatic damage from glucagon suppressing diabetes drugs been underplayed? BMJ. 2013;346:f3680. doi: 10.1136/bmj. f3680. 
150.Manning S, Pucci A, Finer N. Pharmacotherapy for obesity: novel agents and paradigms. Ther Adv Chronic Dis. 2014;5(3):135-48. doi: $10.1177 / 2040622314522848$.

151.Han J, Yi J, Liang F, Jiang B, Xiao Y, Gao S, et al. X3, a mangiferin derivative ,stimulates AMP-activated protein kinase and reduces hyperglycemia and obesity in $\mathrm{db} / \mathrm{db}$ mice. Mol Cell Endocrinol. 2015;405:63-73. doi: 10.1016/j.mce.2015.02.008.

152.Corstens MN, Berton-Carabin-CC, De Vries R, Troost FJ, Masclee AA, Schroen K .Food grade Micro-encapsulation Systems that may induce satiety via Delayed Lipolysis: A Review. Crit Rev Food Sci Nutr. 2015 [Epub ahead of print]

153.Martin LJ. Focoxanthin and its metabolite Fucoxanthinolin Cancer Prevention and Treatment. Mar Drugs. 2015;13(8):4784-98. doi: $10.3390 / \mathrm{md} 13084784$.

154.Look AHEAD Research Group . Eight year weight losses with an intensive lifestyle Intervention: the look AHEAD study. Obesity (Silver Spring). 2014;22(1):5-13. doi: 10.1002/oby.20662.

155.Loveman E, Frampton GK, Shepherd J, Picot J, Cooper K, Bryant J, et al. The clinical effectiveness of and cost effectiveness of long-term weight management schemes for adults: a systematic review. Health Technol Assess. 2011;15(2):1-182. doi: 10.3310/hta15020.

156.Parnell JA, Reimer RA. Prebiotic fiber modulation of the gutmicrobiota improves risk factors for obesity and the metabolic syndrome. Gut Microbes. 2012;3(1):29-34. doi: 10.4161/gmic.19246.

157.Karmali S, Brar B, Shi X, Sharma AM, de Gara C, Birch DW. Weight reduction post-bariatric surgery: a systematic review. Obes Surg. 2013;23(11):1922-33. doi: 10.1007/s11695-013-1070-4.

158.Alhouayek M, Masquelier J, Cani PD, Lambert DM, Muccioli GG. Implications of the anti-inflammatory bioactive lipid prostaglandin D2 glycerol ester in the control of macrophage activation and inflammation by ABHD6. Proc Natl Acad Sci U S A. 2013;110(43):17558-63. doi: 10.1073/pnas.1314017110.

159.Arora E, Khajuria V, Tandon VR, Sharma A, Mahajan A, Gillani ZH, Choudhary N. To evaluate efficacy and safety of Caralluma fimbriata in overweight and obese patients: A randomized, single blinded, placebo control trial. Perspect Clin Res. 2015;6(1):39-44. doi: 10.4103/2229-3485.148812.

160.Bonet ML, Oliver P, Palou A. Pharmacological and nutritional agents promoting browning of white adipose tissue. Biochim Biophys Acta. 2013;1831(5):969-85. doi: 10.1016/j.bbalip.2012.12.002.

161.Bonet ML, Canas JA, Ribot J, Palou A. Carotenoids and their conversion products in the control of adipocyte function, adiposity and obesity. Arch Biochem Biophys. 2015;572:112-25. doi: 10.1016/j. abb.2015.02.022.

162.Xu X, Ying Z, Cai M, et al. Exercise ameliorates high fat diet-induced metabolic and vascular dysfunction and increases adipocyte progenitor cell population in brown adipose tissue. Am J Physiol Regul Integr Comp Physiol. 2011;300(5):R1115-25. doi: 10.1152/ ajpregu.00806.2010.

163.Bostrom P, Wu J, Jedrychowski M, et al. A PGC1- $\alpha$-dependent myokine that drives brown fat like development of white fat thermogenesis. Nature. 2012;481(7382):463-8. doi: 10.1038/nature10777.

164.Seale P, Conroe HM, Estall J, et al. Prdm 16 determines the thermogenic program of subcutaneous white adipose tissue in mice. J Clin Invest. 2011;121(1):96-105. doi: 10.1172/JCI44271.

165.Lecker SH, Zavin A, Cao P, et al. Expression of the irisin precursor FNDC5 in skeletal muscle correlates with aerobic exercise performance in patients with heart failure. Circ Heart Fail. 2012;5(6):812-8. doi: 10.1161/CIRCHEARTFAILURE.112.969543.

166.Zhang Y, Li R, Meng Y, et al. Irisin stimulates browning of white adipocytes through Mitogen-activated protein kinase p38 MAP kinase and ERK MAP kinase signaling. Diabetes. 2014;63(2):514-25. doi: $10.2337 / \mathrm{db} 13-1106$.

167.Spiegelman BM. Banting Lecture 2012: Regulation of Adipogenesis: towards new therapeutics for metabolic diseases. Diabetes. 2013;62(6):1774-82. doi: 10.2337/db12-1665.

168.Wu J, Spiegelman BM. Irisin ERKs the fat. Diabetes. 2014;63(2):3813. doi: $10.2337 / \mathrm{db} 13-1586$.

169.Geurts L, Everard A, Van Hul M, Essaghir A, Duparc T, Matamoros $\mathrm{S}$, Plovier $\mathrm{H}$, et al. Adipose tissue NAPE-PLD controls fat mass development by altering the browning process and gut microbiota. Nat Commun. 2015;6:6495. doi: 10.1038/ncomms7495.

170.MacLean PS, Wing RR, Davidson T, Epstein L, Goodpaster B, Hall KD, et al. NIH working group report: Innovative research to improve maintenance of weight loss. Obesity (Silver Spring). 2015;23(1):7-15. doi: 10.1002/oby.20967. 